OPEN ACCESS

Edited by:

Niccolò Bolli,

University of Milan, Italy

Reviewed by:

Salomon Manier,

Université de Lille, France

Amol Padgaonkar

Prescient Healthcare Group,

United States

Nicola Giuliani,

University of Parma, Italy

${ }^{*}$ Correspondence:

Lawrence H. Boise Iboise@emory.edu

Specialty section:

This article was submitted to Hematologic Malignancies,

a section of the journal

Frontiers in Oncology

Received: 02 November 2020

Accepted: 22 December 2020

Published: 09 February 2021

Citation:

Moser-Katz T, Joseph NS,

Dhodapkar MV, Lee KP and Boise LH (2021) Game of Bones: How Myeloma

Manipulates Its Microenvironment.

Front. Oncol. 10:625199.

doi: 10.3389/fonc.2020.625199

\section{Game of Bones: How Myeloma Manipulates Its Microenvironment}

\author{
Tyler Moser-Katz ${ }^{1}$, Nisha S. Joseph ${ }^{1}$, Madhav V. Dhodapkar ${ }^{1}$, Kelvin P. Lee ${ }^{2}$ \\ and Lawrence H. Boise ${ }^{1 *}$ \\ 1 Department of Hematology and Medical Oncology, Winship Cancer Institute, Emory University, Atlanta, GA, United States, \\ 2 Department of Immunology, Roswell Park Cancer Institute, Buffalo, NY, United States
}

Multiple myeloma is a clonal disease of long-lived plasma cells and is the second most common hematological cancer behind Non-Hodgkin's Lymphoma. Malignant transformation of plasma cells imparts the ability to proliferate, causing harmful lesions in patients. In advanced stages myeloma cells become independent of their bone marrow microenvironment and form extramedullary disease. Plasma cells depend on a rich array of signals from neighboring cells within the bone marrow for survival which myeloma cells exploit for growth and proliferation. Recent evidence suggests, however, that both the myeloma cells and the microenvironment have undergone alterations as early as during precursor stages of the disease. There are no current therapies routinely used for treating myeloma in early stages, and while recent therapeutic efforts have improved patients' median survival, most will eventually relapse. This is due to mutations in myeloma cells that not only allow them to utilize its bone marrow niche but also facilitate autocrine pro-survival signaling loops for further progression. This review will discuss the stages of myeloma cell progression and how myeloma cells progress within and outside of the bone marrow microenvironment.

Keywords: multiple myeloma, bone marrow microenviroment, MGUS, smoldering myeloma, myeloma therapy

\section{INTRODUCTION}

Multiple myeloma (MM) is defined as a clonal proliferation of malignant plasma cells, and it accounts for roughly $10 \%$ of all hematological cancers (1). Myeloma cells retain numerous features of plasma cell biology including a reliance on signals within the bone marrow microenvironment (2). Interestingly, myeloma's precursor states share the same genetic alterations observed in symptomatic MM patients in both the plasma cells and the microenvironment $(3,4)$. In advanced stages, myeloma cells can extravasate from the bone marrow leading to extramedullary plasmacytomas and/or circulating plasma cells in the blood (5). Currently, there are $~ 70$ patient-derived myeloma cell lines (HMCL), representing the most advanced stage of myeloma progression whereby myeloma cells survive independently of the bone marrow microenvironment. To this effect, myeloma cells can be compared to an expansive civilization that strategically taps the resources of its niche and when left unchecked will colonize and overtake its host. The malignant cells compete in a "Game of Bones" against the host's innate defenses and utilize the microenvironment in as a means of gaining an advantage. This review will examine progression of disease from asymptomatic precursor states to $\mathrm{MM}$ while shining a light on the changes myeloma cells induce in themselves and within the microenvironment to enable such 
progression. It will also address the signals that allow myeloma to survive independently of the bone marrow microenvironment in their quest for further growth and expansion.

\section{SPECTRUM OF PLASMA CELL DYSCRASIAS}

\section{Multiple Myeloma}

Historically, establishing the diagnosis of multiple myeloma required both documented bone marrow plasmacytosis (BMPC) $\geq 10 \%$ or an extramedullary plasmacytoma with evidence of end organ damage defined by the CRAB criteria (elevated serum calcium levels, renal insufficiency, anemia, and lytic bone disease). However, in 2014, the International Myeloma Working Group (IMWG) revised the diagnostic criteria to include ultra high-risk patients previously classified as having pre-myeloma or SMM given the $\sim 80 \%$ risk of progression to symptomatic disease at two years. These risk factors include
BMPC $\geq 60 \%$, involved to uninvolved serum free light chain ratio $>100$, and $>1$ focal lesion on whole body MRI or PET-CT (6-9).

Management and therapy selection for myeloma patients can be determined based on risk stratification. Previously, the International Staging System (ISS) divided disease burden of myeloma into three stages. Serum levels of beta-2 microglobulin ( $(32 \mathrm{M})$ and albumin were determined to be the most accurate predictors of disease burden and median survival. Stage I is defined as $ß 2 \mathrm{M}<3.5 \mathrm{mg} / \mathrm{L}$ and serum albumin $\geq 3.5 \mathrm{~g} / \mathrm{dL}$. In Stage III, $ß 2 \mathrm{M} \geq 5.5 \mathrm{mg} / \mathrm{L}$ and serum albumin $<3.5 \mathrm{~g} / \mathrm{dL}$. Stage II refers to the intermediate stage of neither Stage I or III $(10,11)$. Recognizing the important role cytogenetics play in risk stratification, revised ISS (R-ISS) was recently developed still utilizing the ISS, but incorporating both serum lactate dehydrogenase (LDH) levels as well as high risk cytogenetics defined by IgH-MMSET/FGFR3 [t $(4,14)]$ translocations, IgH-MAF $[\mathrm{t}(14,16)]$ translocations, and deletion of the $\mathrm{p}$ arm of chromosome 17 (del17p) (Table 1).

Outside of the R-ISS risk stratification model, there are additional favorable and adverse risk factors that aid clinicians

TABLE 1 | Defining stages of myeloma.

\section{MGUS}

Risk Factors
(1) Serum M-protein $<1.5 \mathrm{~g} / \mathrm{dL}$; (2) non-
IgG subtype (IgM or IgA); (3) serum FLC
ratio $<0.26$ or $>1.65$ )

\section{factor)}

Low-intermediate risk (any 1 abnormal High-intermediate risk (any 2 abnormal factors) High-risk (all 3 factors abnormal) $\quad 58$

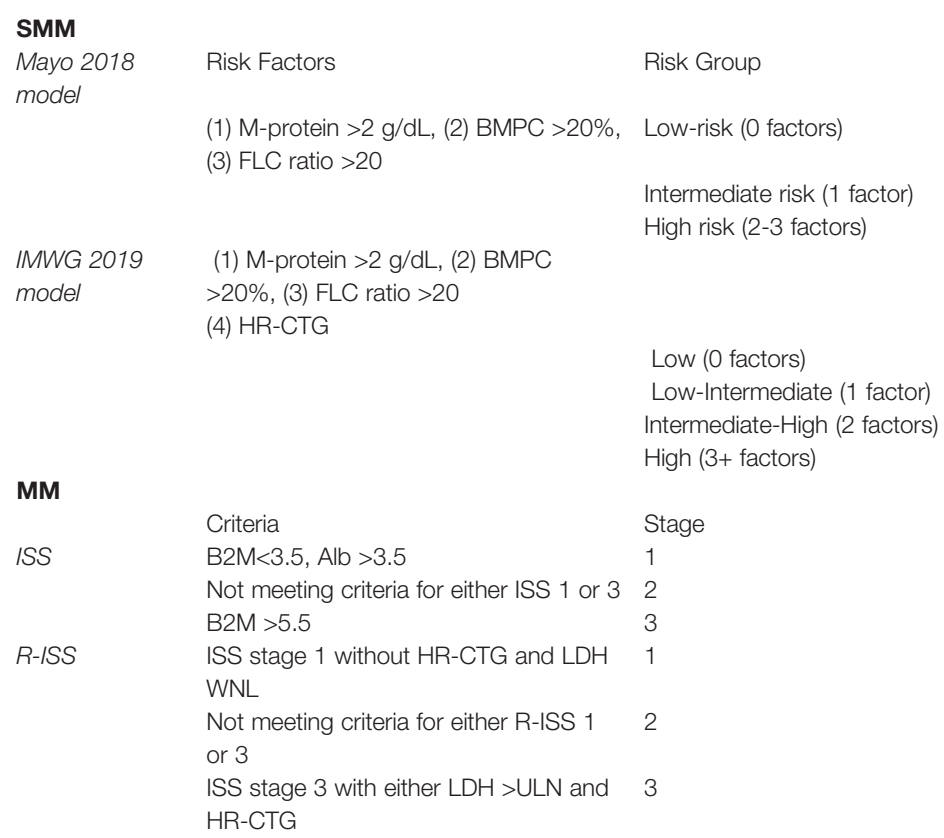

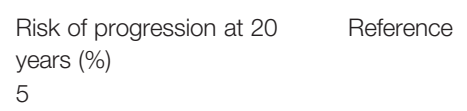

Rajkumar et al. (Lancet Oncology, 2014)

Risk of progression at 2 years

(\%)

5

17

$46 \quad$ Lakshman et al. (BCJ, 2018)

MGUS, monoclonal gammopathy of undetermined significance; SMM, smoldering multiple myeloma; MM, multiple myeloma; BMPC, bone marrow plasma cells; OS, overall survival; ISS,

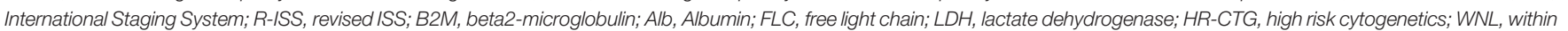
normal limit; ULN, upper limit of normal. 
in appropriate stratification and subsequent treatment of myeloma patients. These factors include additional cytogenetic features, presence of extramedullary disease, gene expression profiling, and plasma cell proliferation. Standard risk myeloma encompasses 80 to $85 \%$ of newly diagnosed myeloma (NDMM) patients and portends good prognosis with a median overall survival (OS) not reached at 10 years (12). Cytogenetic features indicative of standard risk disease includes trisomies of chromosomes $3,5,7,9,11,15,19$, and 21 that is referred to as hyperdiploidy as well as IgH-Cyclin D1 $[\mathrm{t}(11,14)]$, and IgHCyclin D3 $[t(6,14)]$ translocations. High risk patients encompass 15 to $20 \%$ of NDMM patients and have median OS of 5 years (13). In addition to high risk cytogenetic features previously described, additional markers of aggressive disease include complex karyotype, defined as three or more changes on standard karyotype analysis. Another marker of high risk disease is amplification of the $\mathrm{q}$ arm of chromosome 1 (amp1q). Co-occurrence of 1q gain with other high risk markers portends poor prognosis, and patients with $>4$ copies of $1 \mathrm{q}$ are at very high risk for progression following initial treatment (14). Another marker of high risk includes the least common IgH translocation with MAFB [ $t(14,20)]$ which makes up $<1 \%$ of myeloma patients (13). High risk myeloma patients are also identified by disease burden (ISS stage III), proliferation (BMPC labelling index $\geq 3 \%$ via thymidine kinase and C-reactive protein (15)), and presence of extramedullary disease (16).

\section{Multiple Myeloma Precursor Stages}

The presence of a precursor state is not known for most NDMM patients as most diagnoses occur at symptomatic stages. However, studies in 2009 from Drs. Michael Kuehl and Ola Landgren used molecular and biological markers to show that myeloma is preceded in virtually all cases by a premalignant state $(17,18)$. The following two subsections will refer to these precursor states.

\section{Monoclonal Gammopathy of Undetermined Significance}

MGUS was first described in 1961 by Dr. Jan Waldenström who identified a subset of patients with elevated serum and urine immunoglobulin levels without displaying symptoms of malignancy (19). Waldenström labelled this phenomenon a gammopathy, and the term, MGUS, was later coined in 1978 by Dr. Robert Kyle and colleagues (20). The IMWG now defines MGUS as the presence of a serum monoclonal (M) protein or Mprotein at $<3 \mathrm{~g} / \mathrm{dL}$ concentration and $<10 \%$ BMPC with the absence of CRAB criteria (6).

MGUS is found in 3\% of Caucasians over the age of 50 and occurs at a 2 to 3-fold higher rate in African Americans (21, 22). Patients diagnosed with MGUS have a $1 \%$ risk per year of progressing to symptomatic myeloma, and therefore the standard of care is surveillance without intervention (23). Risk of patient progression can be further stratified using three risk factors: presence of a non-IgG M protein (IgA or IgG), Mprotein $>1.5 \mathrm{~g} / \mathrm{dL}$, and abnormal serum free light-chain (FLC) ratio (24) (Table 1). Recently, advancement of technology allowed for detection of precursor cells to MGUS, labelled preMGUS $(3,25)$. As many genomic alterations in MGUS originate in the germinal center, an aberrant clonal population of plasma cells can be formed prior to migration into the bone marrow (26, 27). Furthermore, microenvironment changes present in MGUS have shown to be key regulators in progression to symptomatic stages, and can be targeted in these early stages $(3,28)$.

\section{Smoldering Multiple Myeloma}

SMM is an intermediate clinical stage in progression between MGUS and multiple myeloma initially described in 1980 after observing a series of six patients with BMPC $>10 \%$ that continued to have stable disease without treatment for $>5$ years (29). SMM is defined as the presence of an M-protein at $\geq 3 \mathrm{~g} / \mathrm{dL}$, and/or BMPC percentage of $>10 \%$ with no evidence of end organ damage defined by the CRAB criteria (hypercalcemia, renal failure, anemia, bone lesions) (30). After the IMWG revised the diagnostic criteria of myeloma, a subset of patients previously classified as having SMM were now reclassified as having symptomatic myeloma. However, this reclassification ultimately only affected a small proportion of SMM patients, and the challenge still remained how to appropriately risk-stratify the remaining patients. SMM is a very heterogeneous disorder encompassing patients that will progress in the first two years and patients with stable low-level disease more than ten years after diagnosis. How then, do we identify which patients are at the highest risk of progression, and how do we safely manage them?

The Mayo 2018 model, also known as the 20/2/20 model, uses three independent risk factors of progression to myeloma: (1) a serum FLC ratio $>\underline{20}$, (2) M-protein $>\underline{2} \mathrm{~g} / \mathrm{dL}$, and (3) BMPC $>\underline{20} \%$. Depending on whether the patient has either 0,1 , or $2-3$ of these factors, they are categorized as having either low, intermediate, or high risk SMM corresponding to a $5 \%, 17 \%$, or $46 \%$ risk of progression at 2 years (31). The IMWG validated this model using a retrospective cohort, but added the high-risk cytogenetic features $t(4,14)$, gain(1q), del(17p), and $\operatorname{del}(13 q)$. Interestingly hyperdiploidy has been shown to be an adverse prognosticator in SMM despite its opposite meaning in MM (32). In this model, SMM patients were grouped into four risk categories (low risk, low-intermediate risk, intermediate risk, high risk) associated with a 2 -year progression rate of $3.7 \%, 25 \%$, $49 \%$, and $72 \%$, respectively (33) (Table 1 ).

Historically, observation was also the standard of care for SMM as with MGUS. However, recently published data has shown the benefit of early intervention with the immunomodulatory agent (IMiD) lenalidomide in high-risk SMM in terms of delaying progression to myeloma (34). The efficacy of using IMiDs in SMM illustrates the role that the microenvironment has in facilitating MM progression. Ongoing clinical trials continue to investigate different therapeutic strategies in SMM, as this continues to be an evolving area of research.

\section{Extramedullary Multiple Myeloma}

Extramedullary multiple myeloma (EMM) refers to hematogenous spread of clonal plasma cell tumors leading to soft tissue tumors at anatomic sites outside the bone marrow (35). 
This is a separate diagnosis from solitary plasmacytomas which originate from the underlying bone marrow and grow through the cortical bone $(36,37)$. EMM can present in the liver, skin, central nervous system, pleura, kidneys, lymph nodes, and pancreas and is present in $6 \%-8 \%$ of NDMM cases and 10$30 \%$ of relapsed myeloma patients $(38,39)$. EMM may also present as plasma cell leukemia (PCL), an aggressive variant of the disease with $>20 \%$ or $\geq 2^{\star} 10$ (9) circulating plasma cells in the blood (40). PCL can either present de novo, known as primary PCL, or more commonly as a progression from already diagnosed myeloma, known as secondary PCL.

Extramedullary disease and PCL are considered high risk entities and associated with a poor prognosis with a median OS of less than 6 months (37). Profiling of extramedullary tumors reveals differences from malignant bone marrow plasma cells. Cytogenetics that indicate standard risk myeloma such as hyperdiploidy and $t(11,14)$ are mainly found in BMPC and rarely found in extramedullary plasmacytomas whereas $t(4,14)$ is more commonly seen in $\operatorname{EMM}(35,41)$. However, PCL, while heterogeneous, does have a higher incidence of $\mathrm{t}(11,14)$ translocations $(40,42)$. In relapsed patients, EMM cells undergo a shift from secretion of intact IgG to light chain, and most HMCL secrete only light chain, demonstrating its correlation with myeloma progression (43). The changes in molecular and protein expression that allow myeloma cells to survive and spread outside of the microenvironment will be addressed in a subsequent section of this review.

\section{THE ROLE OF THE BONE MARROW MICROENVIRONMENT}

In 1889, Stephen Paget introduced his "seed and soil" hypothesis which postulated that tumor cells (seed) grow preferentially in selective microenvironments (soil) $(44,45)$. We have seen that plasma cells undergo genomic alterations in the germinal center prior to MGUS $(26,27)$. Once this clonal population arrives in the bone marrow, it gains access to a wide array of microenvironment signals that facilitate plasma cell survival. Recent studies have found little difference between the microenvironments of MGUS and myeloma, demonstrating that the "soil" has a role in shaping the malignant progression $(3,46)$. The bone marrow microenvironment produces prosurvival signals for non-malignant long-lived plasma cells, which can live throughout the lifetime of the host, and secrete antibody titers as part of the adaptive immune response (2). Myeloma cells, the aggressive counterparts, use the supportive surrounding stromal cells, osteocytes, and endothelial cells to further their growth. Myeloma precursor states have been shown to mediate progressive growth in vivo in humanized mouse models supporting a dominant role for the microenvironment or tumor-extrinsic signals in regulating tumor growth (46). Initial small changes in the microenvironment or molecular changes to myeloma cells themselves cause an expansion of the plasma cell niche throughout the bone marrow.

\section{Molecular Changes Driving Myeloma Growth}

Myeloma cells undergo numerous molecular changes and genetic events which allow proliferation and induce further changes in the bone marrow microenvironment. One family of proteins commonly dysregulated in myeloma are D-type cyclins (47). D-type cyclins are cell cycle proteins that activate cyclin dependent kinase 4 (CDK4) and CDK6, which phosphorylate and inactivate $\mathrm{Rb}$ allowing for $\mathrm{E} 2 \mathrm{~F}$ activation and cell cycle progression (48). Primary genetic translocations such as $t(11,14)$ and $t(6,14)$ directly drive constitutive expression of cyclin D1 and D3 respectively $(47,49,50)$. Another translocation $t(4,14)$ which increases the expression of the histone methyltransferase MMSET (NSD2) also indirectly drives activation of cyclin D2 $(47,51)$. Cyclin D2 can also be dysregulated through $t(14,16)$ and $\mathrm{t}(14,20)$ translocations which drive transcription factors that target Cyclin D2 (47). Although infrequent, biallelic inactivation of $\mathrm{Rb}$ itself is a subclonal mutation that occurs in $3 \%$ of tumors (52). Rb is found on chromosome $13 \mathrm{q}$, and this deletion of this region is the most common mutation in myeloma, frequently accompanying $\mathrm{t}(4,14), \mathrm{t}(14,16)$, and $\mathrm{t}$ $(14,20)$ translocations $(53,54)$. Recently it was shown that monoallelic deletion of two other genes on $13 \mathrm{q}$ which code for Mir15A and Mir16-1 resulted in development of MGUS in wild type C57BL/6 mice and progression of myeloma in the $\mathrm{Vk}^{\star} \mathrm{Myc}$ multiple myeloma mouse model (55).

Myeloma upregulates oncogenes that are typically associated with proliferation in cancer. One such gene is MYC, and its deregulation typically leads to a more aggressive disease phase (56). MYC translocations are found in $15 \%$ of human myeloma tumors (57) and include both IgH-MYC translocations $[\mathrm{t}(8,14)]$ and IgL-MYC translocations $[\mathrm{t}(8,22)]$. The MYC locus is the most common source of light chain translocations accounting for $40 \%$ of these anomalies, and lambda light chain translocations portend a particularly poor outcome compared to kappa light chain translocations (58). Another pathway that is involved in myeloma proliferation is RAS signaling. A secondary mutation that is uncommon in MGUS, KRAS, and NRAS mutations are each found in $20 \%$ of NDMM patients (27, 59). KRAS and NRAS mutations appear to not uniformly activate MAPK signaling pathways and actually lead to distinct downstream transcriptional signatures (60). Interestingly, FGFR3 mutations, which are mutually exclusive with RAS mutations appear to induce MAPK signaling more effectively $(60,61)$. Finally, the MAPK pathway can be activated by BRAF mutations. BRAF is mutated in $4 \%$ of patients with the V600E mutation being the most common (62). Additionally, recent studies have shown a role for cytidine deaminases such as AID and APOBEC in mediating genomic instability in MM cells (63). The expression of these genes, however, is also dependent on interactions with the microenvironment (64).

\section{Extracellular Matrix}

The bone marrow microenvironment provides a layered structure called the extracellular matrix (ECM) which acts as 
the "home base" for myeloma cells. Homing to the bone marrow is mediated by interaction of myeloma receptor CXCR4 with the chemokine SDF1 $\alpha$ (65). This causes a subsequent migration to the stromal compartment of bone marrow. There, it will interact with ECM proteins or other native bone marrow cells.

The ECM consists of proteins such as fibronectin, collagen, osteopontin, hyaluronan, and laminin. Adhesion of myeloma cells has been shown to be important for survival and drug resistance $(66,67)$. A method of cell-ECM adhesion is activation of integrins, and myeloma cells have shown preference toward very large antigen- 4 (VLA-4) aka integrin $\alpha 4 \beta 1$ and integrin $ß 7$ (ITGB7) (68-70). Binding of VLA-4 to fibronectin of the ECM induces activation of nuclear factor $\kappa \mathrm{B}(\mathrm{NF \kappa B})$ leading to cell adhesion-mediated drug resistance (CAM-DR) and pro-survival signaling (71). ITGB7 can be regulated by the MAF gene, and as a result, patients with $\mathrm{t}(14,16)$ have elevated levels of ITGB7 (51). ITGB7 is necessary for myeloma cell survival and CAM-DR, and has been shown to be constitutively active in myeloma cells (70, 72). Additional integrins such as VLA5 and the beta 5 integrin CD56 play a smaller but active role in myeloma progression (68, 73) (Figure 1).

Syndecan-1 or CD138 is a heparan sulfate proteoglycan and a surface marker of myeloma cells. It binds to type I collagen and induces expression of matrix metalloproteinase 1 (MMP1) to promote tumor invasion, bone resorption, and angiogenesis (74, 75). Additionally, syndecan-1 levels on cells correlate with cell survival and growth (76). Heparanase has an intricate interplay with syndecan-1, either causing its clustering and increased adhesion to the ECM or inducing its shedding $(77,78)$. Soluble syndecan-1 has been shown to promote myeloma tumor growth

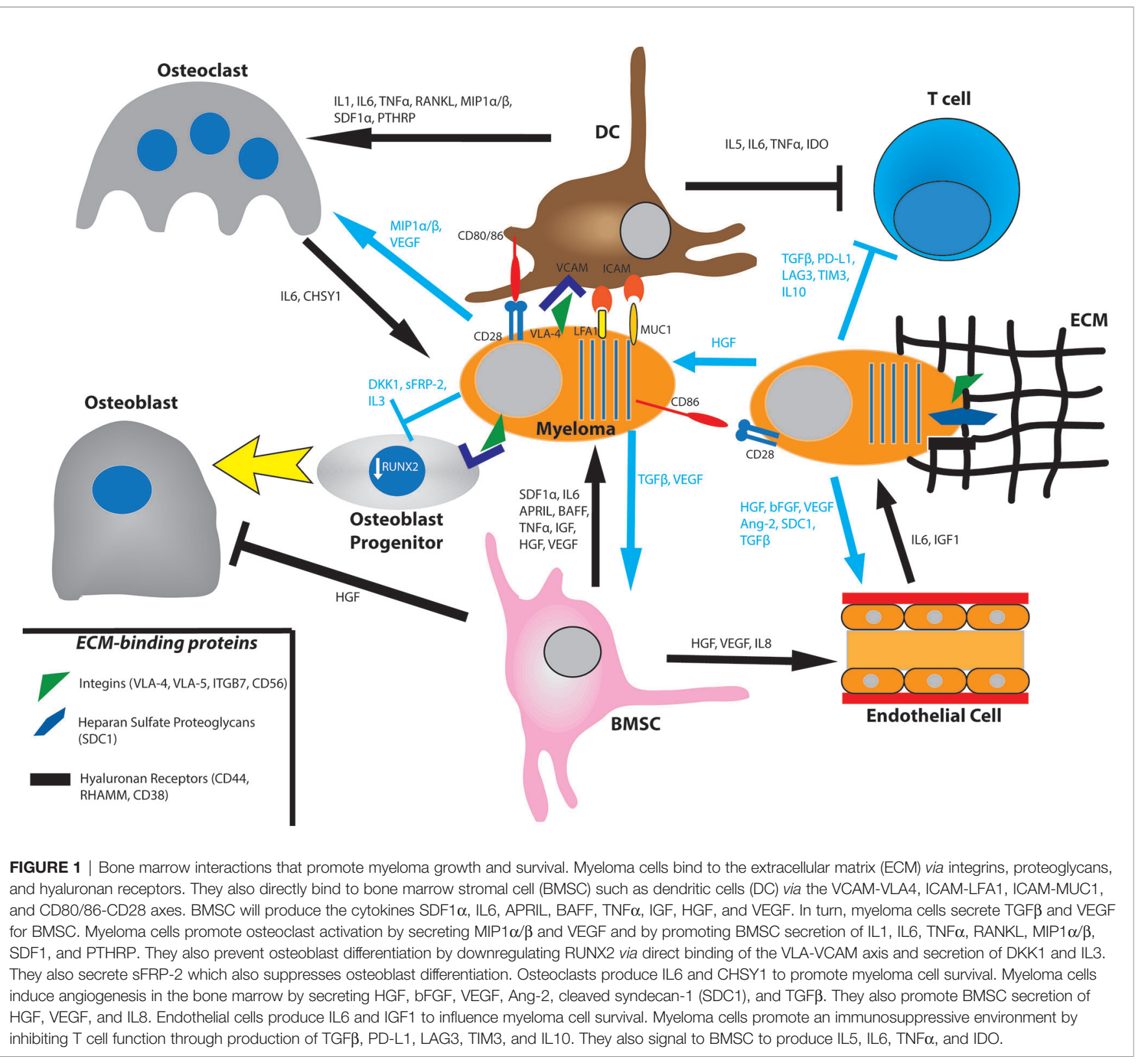


in vivo (79). Finally, CD44, RHAMM, and CD38 are hyaluronan receptors (67). Hyaluronan is a secreted scaffold protein in the bone marrow. While certain splice variants of CD44 and RHAMM are active in the bone marrow as receptors for hyaluronan and osteopontin, they are generally more involved in extramedullary myeloma. Both proteins regulate the SDF1 $\alpha$ / CXCR4 axis, and cell-ECM adhesion with RHAMM is more involved in cell motility (67). CD38 is another hyaluronic acid interacting partner that is expressed in high levels in plasma cells but low levels in other lymphoid and myeloid cells making it an effective target for antibody therapies like daratumumab and isatuximab (80)

\section{Myeloma-Stroma Cell-Cell Contact}

Binding of VLA-4 of a myeloma cell to VCAM of an adjacent stromal cell promotes downstream signaling pathways that activate NFKB and cause cellular survival and proliferation (74). Another myeloma receptor, lymphocyte functionassociated antigen 1 (LFA1), will bind to ICAM-1 of an adjacent bone marrow stromal cell (BMSC). LFA1 is an integrin composed of $\alpha \mathrm{L}$ and $\beta 2$ subunits and is associated with poor prognosis and disease progression in patients as well as increased proliferation in mice $(81,82)$. Mucin 1 (MUC1) is another transmembrane binding partner of ICAM-1 that has been shown to drive myeloma progression (Figure 1). MUC1 will induce proliferation in multiple myeloma by signaling via a ß-catenin/TCF4 mechanism to drive MYC gene expression (83).

Plasma and myeloma cells also express CD28, a transmembrane protein classically known for its role in $\mathrm{T}$ cell co-stimulation. During this process, MHC of an antigen presenting cell (APC) will first bind to the T cell receptor. The $\mathrm{T}$ cell is not fully activated unless CD80/86 of an APC binds to CD28 of a T cell, inducing survival, proliferation, and effector function in $\mathrm{T}$ cells (84). Plasma cells retain this CD28 prosurvival signaling capacity, and binding with CD80/86 of a BMSC, e.g., dendritic cell confers survival throughout the lifetime of the host $(85,86)$. Plasma and myeloma cells are dependent on CD28 signaling through both the PI3K and Vav signaling pathways $(87,88)$. Knockout of CD28 leads to decreased antibody titers of long-lived plasma cells in mice, and knockdown of CD28 or CD86 with short hairpin RNA leads to myeloma cell death in HMCL $(86,88,89)$ (Figure 1).

\section{Myeloma-Bone Marrow Stromal Cell Pro- Survival Cytokines}

Multiple myeloma cells also pave the way for their own survival and proliferation by inducing cytokine secretion in BMSC. Direct binding of plasma and myeloma cells to BMSC leads to downstream pathways such as MAPK, NOTCH, and PI3K and cause subsequent transcription and secretion of numerous cytokines. One such cytokine is interleukin-6 (IL6), which has roles in myeloma growth, survival, migration, and drug resistance. IL6 binds to its cognate IL6-receptor (IL6R) and signals through MEK/MAPK, JAK/STAT, and PI3K/Akt pathways (90-92). It also increases dependence on Mcl-1, an anti-apoptotic Bcl-2 protein that is essential for plasma and myeloma cell survival. IL6 upregulates Mcl-1 in a STAT3 dependent manner and induces phosphorylation of Bim, thus increasing affinity of Bim for $\mathrm{Mcl}-1$ over $\mathrm{Bcl}-2 / \mathrm{Bcl}-\mathrm{x}$. This increased binding of the two proteins ultimately leads to stabilization of Mcl-1 $(93,94)$.

In the absence of IL6, two other cytokines, B-cell activating factor (BAFF) and a proliferation inducing ligand (APRIL) have been shown to have a protective effect on myeloma cells particularly from treatment with corticosteroid (95). BAFF is a member of the tumor necrosis factor (TNF) family and is expressed on the surface of BMSC as well as in a cleaved soluble form. It has been shown to stimulate B cell growth, and, additionally, ligation of its receptors BAFF-R and TACI leads to increased proliferation and survival in myeloma cells $(96,97)$. APRIL is a secreted protein that will bind to TACI and B-cell maturation antigen (BCMA), a protein which has recently become a target for myeloma CAR-T cell therapy with an $88 \%$ response rate $(98,99)$. BAFF and APRIL-mediated signals also impact survival and growth signals to $\mathrm{MM}$ from surrounding dendritic cells (100). They are overexpressed in myeloma cells compared to normal plasma cells illustrating the importance of these cytokines (95). APRIL and BCMA promote cell growth (via MAPK and NFKB) and immunosuppression (via PD-L1, TGF$ß$, and IL10) in myeloma cells (98).

Another member of the TNF family involved in myeloma growth and survival in the bone marrow microenvironment is TNF $\alpha$. TNF $\alpha$ is a mediator of inflammation and has been found to be significantly higher in supernatants of patients with bone disease than those without (101). While TNF $\alpha$ signaling itself causes a modest increase in proliferation, it induces expression of adhesion molecules resulting in a 2-4 fold increase in binding of myeloma cells to BMSC. It also results in a significant increase in IL6 secretion. Interestingly, $\mathrm{TNF} \alpha$ levels decrease with thalidomide treatment which may be a result of downstream effects of the drug's immunomodulatory effects on bone marrow myeloma cells (102).

Myeloma cells induce BMSC to secrete numerous growth factors. Among them, insulin-like growth factor (IGF) appears to have a sustained and pronounced effect on myeloma proliferation and antiapoptotic signaling. IGF binds to the tyrosine kinase receptor IGF-1R, and additionally influences proteasome and telomerase activities in myeloma cells. IGF is also implicated in drug resistance to cytotoxic chemotherapy, dexamethasone, and proteasome inhibitors (103). It primes myeloma cells to respond to other cytokines and to produce pro-angiogenic cytokines. BMSCs also produce other growth factors such as hepatocyte growth factor (HGF), basic fibroblast growth factor (bFGF) and vascular endothelial growth factor (VEGF) which influence osteoclast activation and angiogenesis (74) (Figure 1).

\section{Osteoclast Interactions}

Bone lesions result from osteoclast activation to enable further space for myeloma proliferation in the bone marrow. To directly activate osteoclasts, myeloma cells secrete macrophage inflammatory protein- $1 \alpha(\mathrm{MIP} 1 \alpha)$ and MIP1ß. MIP1 $\alpha$ binds 
to $\mathrm{C}$-chemokine receptor 1 (CCR1) and CCR5 while MIP1ß binds to CCR5 and CCR8 to induce osteoclast formation and activity (104-106). MIP1 $\alpha$ has been shown to lead to bone destruction, BMSC adhesion, and tumor burden in SCID mice with multiple myeloma (104). In turn, osteoclasts secrete IL6 to stimulate proliferation and growth of not only myeloma cells but other osteoclasts as well (107). Myeloma-osteoclast interaction also upregulates Chondroitin synthase 1 (CHSY1), which induces Notch signaling promoting the survival of myeloma cells (108). Notch signaling, particularly Notch3 and Notch4 stimulation leads to recruitment of osteoclast precursors and increased bone resorption $(109,110)$.

Interactions between myeloma cells and BMSCs also leads to production of cytokines that stimulate osteoclastogenesis. Binding of VLA4 with VCAM promotes secretion of cytokines such as IL1, IL6, TNF $\alpha$, and parathyroid hormone related peptide (PTHRP) which promote osteoclast growth (111). Binding of VLA4 and VCAM also lead BMSC to produce receptor activator of $\mathrm{NF \kappa B}$ ligand (RANKL). RANKL will bind to its receptor RANK to stimulate osteoclast activation and differentiation and bone lysis $(111,112)$. RANKL, MIP1 $\alpha$, and IL11 are upregulated by 38 MAPK in BMSCs, and inhibiting p38 MAPK decreases osteoclastogenesis and bone resorption (113) (Figure 1). The bone matrix glycoprotein, osteopontin, and the pro-inflammatory cytokine IL17 have also been implicated in osteoclastogenesis and bone resorption. They have been shown to be associated with poor prognosis and osteolytic lesions in patients (114-116).

\section{Osteoblast Interactions}

Myeloma cells also disrupt bone homeostasis by inhibiting osteoblast production and activation. Osteoblasts and BMSC produce osteoprotegerin (OPG) which inhibits the development of bone disease by competing for binding of RANK with RANKL (117). Binding of OPG with RANK prevents osteoclast maturation and activation (118). The ratio between RANKL and OPG is important prognostic indicator in patients and can be influenced in numerous ways (119-121). One way is binding of VLA4 on myeloma cells to VCAM of BMSCs which decreases secretion of OPG and increases secretion of RANKL, thereby tipping the balance in favor of osteoclasts $(111,112)$. Other factors which augment the RANKL/ OPG ratio are activin A and sclerostin $(122,123)$. Sclerostin is cysteine knot protein which induces apoptosis in osteoblasts and inhibits bone formation (124). Activin A, a member of the TGF$ß$ superfamily, signals through numerous pathways to promote osteoclast differentiation and is a marker of poor prognosis (122, 125). Interestingly, IL3 can increase osteoclastogenesis by regulating activin A levels (126).

Myeloma cells can also prevent the maturation of osteoblast progenitor cells. Binding of VLA4 of myeloma cells to VCAM of osteoblast progenitors downregulates the activity of RUNX2, a transcription factor that is necessary for the differentiation of osteoblastic cells (127). In addition to increasing the RANKL/ OPG ratio, IL7 secretion by BMSC also decreases RUNX2 activity and osteoblast differentiation $(119,127,128)$. Recent studies from the Croucher lab have shown that MM-osteoblast interactions may also be important for maintaining dormancy of tumor cells (124)

Secretion of the cytokines Dickkopf 1 (DKK1) and Frizzled related protein 2 (sFRP-2) by myeloma cells contributes to bone resorption as well. DKK1 and sFRP-2 inhibit the canonical Wnt pathway which is responsible for the differentiation of osteoblast progenitor cells $(127,128)$. DKK1 and sFRP-2 are expressed in multiple myeloma cells of patients with bone lesions. Recombinant DKK1 and sFRP-2 or conditioned media containing either of the two cytokines inhibit differentiation of osteoblast precursor cells in vitro and suppress in vitro bone mineralization $(129,130)$. Interestingly, immunodepletion of sFRP-2 led to increased bone restoration suggesting it is necessary for bone resorption. Osteoblast differentiation may take place via the bone morphogenic protein 2 (BMP2) pathway. sFRP-2 as well as IL3 inhibit this pathway, thereby stunting osteoblast activation. Additionally, secretion of the cytokines TGF- $\beta$ and HGF by BMSC promote osteoclast generation while limiting osteoblast activity $(74,131)$ (Figure 1).

\section{Endothelial Cell Interactions}

Angiogenesis is the creation of new blood vessels through the use of endothelial cells. Patients with progressive myeloma disease show increased level of microvessel density (MVD), a measure of angiogenesis, when compared to those with inactive MGUS (132). This is because myeloma cells crowd the bone marrow microenvironment and generate hypoxic tumors, so they upregulate angiogenesis to deliver oxygen and nutrients while removing catabolites. In the presence of hypoxic conditions, myeloma cells upregulate hypoxia induced factor $1 \alpha$ (HIF $1 \alpha)$, which regulates transcription of pro-angiogenic cytokines including HGF, bFGF, VEGF, and Angiopoietin-2 (Ang-2). Myeloma cells may also constitutively produce these cytokines due to genetic mutations or oncogene activation (133).

Adhesion of myeloma to the ECM increases angiogenesis. Expression of adhesion molecules VLA4, LFA1, and CD44 have been shown to correlate with increased angiogenesis in active myeloma (134). Syndecan-1 has been shown to have a prominent role in bone marrow angiogenesis as well. Syndecan-1 is correlated with MVD and facilitates binding of growth factors, particularly HGF, to cells. Not only can syndecan-1 potentiate the surface binding of HGF to cells, but it can also be shed in a soluble form that complexes with HGF to increase potency (135, 136). Myeloma cells also facilitate degradation of the ECM using matrix metalloproteinases (MMP) and heparanase to allow migration of endothelial cells into the surrounding tissue $(137,138)$.

Myeloma cells stimulate BMSCs to secrete HGF, VEGF, and IL8 to induce neovascularization (139). In turn, endothelial cells will produce IGF1 and IL6 to promote myeloma cell growth. This process can induce an autocrine loop in endothelial cells as they produce VEGF, platelet-derived growth factor (PDGF), Ang-1, HGF, and IL1 to further promote angiogenesis (140) (Figure 1).

\section{Immune Cells}

While the previous subsections have addressed allies that myeloma uses to advance itself in the Game of Bones, 
myeloma cells have an antagonist in the form of antitumor cells in the bone marrow. To overcome this, $\mathrm{MM}$ and its precursor MGUS are associated with several alterations in both innate and adaptive immunity. Immune cells increased in MM include regulatory $\mathrm{T}$ cells, IL-17-producing $\mathrm{T}$ cells, and terminally differentiated effector $\mathrm{T}$ cells, however, immunosuppression and exhaustion of these cells was present as early as the MGUS stage $(3,141)$. The bone marrow increases CD4(+) regulatory $\mathrm{T}$ cells and decreases CD4(-)CD8(-) regulatory $\mathrm{T}$ cells, and this correlates with increased disease burden (142). Myeloma cells produce proteins such as TGF- 3 , PD-L1, LAG3, TIM3, and IL10 that contribute to the immunosuppressive phenotype and T cell anergy (Figure 1). Interestingly, these proteins are upregulated in myeloma cells by binding of APRIL to BCMA (98). CD28 ligation with CD80/86 has also been shown to cause BMSC secretion of IL6 and IDO. This occurs via "back signaling" of CD80/86 to activate the PI3K pathway. While IL6 normally activates $\mathrm{T}$ cells, IDO catabolizes tryptophan in the microenvironment into the toxic metabolite kynurenine. This results in T cell anergy via GCN2 kinase-mediated sensing of depleted intracellular tryptophan pools $(143,144)$. Interestingly, a subset of endothelial cells express low levels of CD80/86 as well as CD40 and ICOS-L in myeloma patients which can trap a population of $\mathrm{T}$ cells and stimulate them to induce immunosuppressive proteins (145). Autologous dendritic cells stimulated with tumor antigen can be used to activate T cells ex vivo to expand and attack the tumor. Emerging treatments such as targeted antibodies, checkpoint inhibitors and CAR-T cell therapy have aimed to increase the potency of the immune response $(28,141)$. Currently, advances in mass cytometry and RNA sequencing single cell analyses are being used to identify the immune checkpoint signature of the microenvironment (25). These methods have identified immunosuppressive phenotypes such as regulatory $\mathrm{T}$-cell suppression, secretion of suppressive cytokines and interferons, and increased expression of PD-1 on CD8(+) T and NK cells as early as MGUS (146).

Myeloid derived suppressor cells (MDSC) have been shown to promote immune suppression and angiogenesis in multiple myeloma. They induce myeloma cell survival and proliferation by causing AMPK phosphorylation in myeloma cells. This increases levels of the anti-apoptotic proteins MCL-1 and BCL-2 and the autophagy marker LC3II (147). Myeloma cells in turn will cause an increase of MCL-1 expression and survival in MDSC (148). Another cell type, plasmacytoid dendritic cells (pDC), contribute to immunosuppression of the microenvironment when in direct contact with myeloma cells. While pDC can normally be activated to cause apoptosis of myeloma cells, pDC-myeloma binding via E-cadherin can convert $\mathrm{pDC}$ into tumor promoting cells (149). Myeloma cells use cell-cell contact to court the pDC to their advantage and signal downstream to inhibit pDC secretion of interferon- $\alpha$ (IFN- $\alpha$ ) (149).

Natural killer (NK) cells induce cell death in myeloma cells via granzyme and perforin release and other proapoptotic ligands (150). Myeloma cells express CD1d and are also highly sensitive to lysis by NK cells. PD-L1 of a myeloma cell can bind PD-1 of NK cells to suppress their cytotoxic effect of myeloma cells. NK cells are a target of numerous therapies aimed at the immunosuppressive microenvironment. Lenalidomide can be added to checkpoint inhibitors to abrogate this effect and stimulate NK to target myeloma cells (151). The anti-SLAMF7 antibody elotuzumab can also be used to activate NK cells and mediate their activity in myeloma (152). In addition to targeting myeloma cells, the antiCD38 antibody, daratumumab, also depletes CD38(+) regulatory cells in the bone marrow thus promoting an immune response (153). Recently, daratumumab has been shown to specifically stimulate NK cell activity in myeloma by selectively targeting CD38(+) NK cell populations (154). NK cells and other bone marrow resident immune cells are avenues for immunotherapy and have yielded some initial success in treating myeloma patients at precursor stages $(28,155-158)$.

\section{MYELOMA TAKEOVER BEYOND THE MICROENVIRONMENT}

While myeloma cells can be seen circulating in peripheral blood in advanced stages, most EMM is characterized by plasmacytomas in adjacent tissues and organs. Myeloma cells must develop the capacity to extravasate through stroma and ECM into the blood and navigate challenges such as building their own microenvironment in sites outside of the bone marrow. As the disease advances, cells undergo molecular and genomic alterations to promote autocrine loops that facilitate survival and proliferation away from its bone marrow sanctuary. It is notable that although extramedullary growth is a feature of advanced MM, circulating tumor cells can be detected even in early stages of MM (159). This section will explore a new landscape for the Game of Bones and how myeloma cells can undergo changes to survive and expand their niche independently of bone marrow signals.

\section{Extravasation Model}

While little is known about myeloma extravasation from the bone marrow, we can follow an adaptation of the leukocyte multistep model of extravasation and homing (Figure 2). In the standard model, cells first home to an environment as a result of chemoattractants. This is followed by adhesion of the cell to vascular endothelial cells and reorganization of the cytoskeleton to migrate through gaps between these endothelial cells. During this process, the cell degrades basement membrane and extracellular matrix to allow passage until its penetration through (160) (Figure 2A). We can reverse this first step for the myeloma cell extravasation model as they must first shed homing signals which tether them to the bone marrow. They must also reduce their affinity to ECM and cells that are specific to the bone marrow and upregulate migratory proteins. Finally, myeloma cells must also degrade the basement membrane to allow passage through gaps created in the bone marrow structure (Figure 2B). Once the myeloma cells are in circulation, they may re-enter the vasculature in other marrow compartments via the standard leukocyte model of extravasation. They may also form tumors in organs or remain circulating in the blood in the case of PCL. 

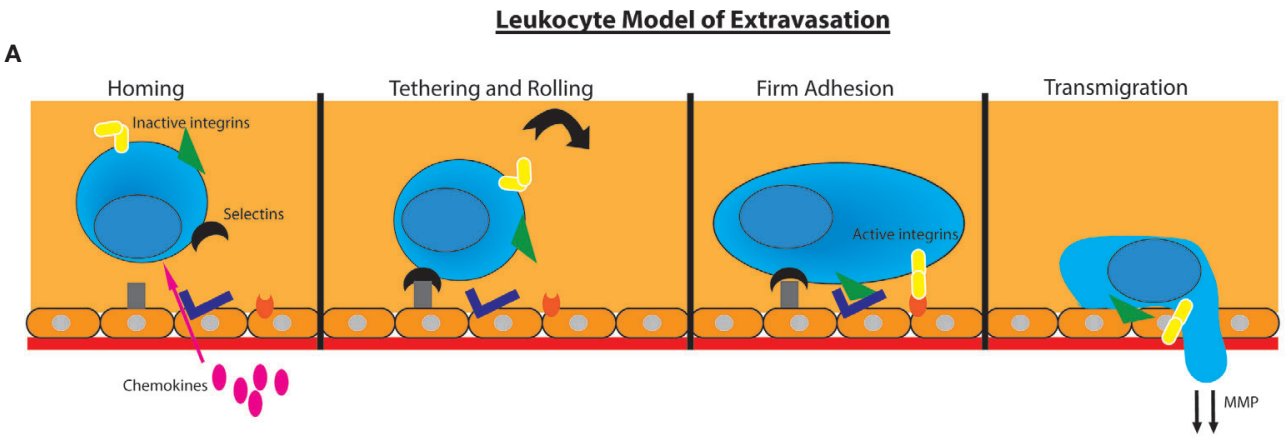

Myeloma Model of Extravasation

B

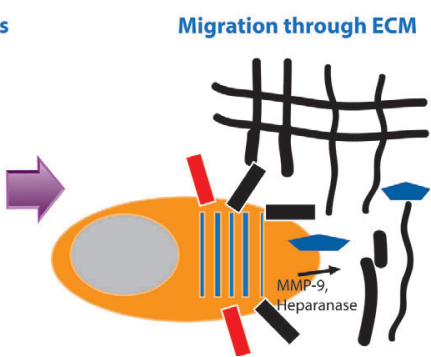

FIGURE 2 | Models for leukocyte and myeloma cell extravasation. (A) Standard leukocyte multistep model of extravasation. The leukocyte in the bloodstream receives homing signals from chemokines. This is followed by weak adhesion to the endothelium and rolling along the surface. Integrins such as VLA4 and LFA1 are activated to form tight adhesion to the endothelium. The leukocyte then reorganizes its cytoskeleton and degrades the basement membrane to transmigrate through. (B) Model of myeloma extravasation out of the bone marrow. Myeloma cells downregulate receptors used for homing to the bone marrow. They alter adhesion molecules by downregulating integrins and increasing hyaluronan receptors such as CD44 and RHAMM and expression of focal adhesion kinase (FAK). The myeloma cell will secrete MMP-9 and heparanase as well as induce production of MMP-9 via endothelial cells to degrade the extracellular matrix (ECM). Heparanase secretion can cause shedding of SDC1 which also contributes to cell motility. The myeloma cell will then reorganize its cytoskeleton and migrate through the ECM.

In order to home to the bone marrow, myeloma cells depend on chemokine signaling. The SDF1 $\alpha /$ CXCR4 axis is the myeloma homing pathway most extensively characterized, and impairment of signaling between these molecules is associated with extramedullary transformation (39). Myeloma also depends on CCR1 and CCR2 signaling to regulate migration. Patients with active disease express significantly lower amounts of CXCR4, CCR1, and CCR2 than those with non-active disease, and expression of at least one of these receptors portends favorable clinical outcome (161). Additional chemokine receptors such as CXCR5 and CCR7 are downregulated to promote cell motility and decrease sensitivity to B and T cell cytokines (162).

Myeloma cells alter their adhesion properties to extravasate and migrate through the ECM. EMM plasma cells decrease expression of CD56 while increasing expression of certain CD44 isoforms that are important for proliferation and motility (163). In murine models, decreased expression of P-selectin and VLA4 are associated with increased extramedullary disease (164). Extramedullary myeloma cells also favor focal adhesion kinase (FAK), a protein that mediates an invasive and migratory phenotype. Patients with EMM have significantly increased expression of FAK mRNA compared with patients without extramedullary disease (165). The tetraspanin family of proteins is another family that modulates myeloma adhesion and migration. Two such proteins, CD81 and CD82, are downregulated in HMCL, and exogenous overexpression of these proteins reduces cell motility, invasion, and secretion of MMP-9 (166).

Finally, myeloma cells must degrade the ECM to allow passage through. MMP-9 will degrade basement membrane, and its secretion leads to increased invasion of tumor cells. HMCL have been shown to constitutively secrete MMP-9, and its expression is enhanced by HGF secretion by endothelial cells. Moreover, some HMCL can produce HGF, thus sustaining a loop of increased MMP-9 degradation. Interestingly, SDF1 $\alpha$ stimulates MMP-9 production in mouse myeloma model suggesting that SDF1 $\alpha$ may have pleiotropic effects in both myeloma cell homing and invasion (167). Myeloma cells also produce heparanase, an enzyme that cleaves heparanase sulfate chains of adhesive proteoglycans such as syndecan-1. Production of heparanase increases motility of myeloma cells and induces a migratory phenotype (168). In part, heparanase and syndecan appear to regulate one another throughout the progression of myeloma and EMM (Figure 2B).

\section{Extramedullary Multiple Myeloma Molecular Changes}

Comparison of myeloma cells at extramedullary sites with bone marrow myeloma cells revealed increased subclonal mutations in the extramedullary sites. Morgan et al. proposed a model of myeloma progression that follows the Darwinian mechanism of species evolution. In this model, myeloma cells undergo primary 
mutations that underlie their growth and expansion. When a bottleneck is applied, subsequent mutations of cells are selected for, thus resulting in surviving subclonal genetic populations (169). In addition to drug treatment, bottlenecks may refer to hypoxia, cell-competition in the microenvironment, and other novel environmental differences in extramedullary sites. Myeloma cells can migrate to other less populated marrow compartments or soft tissue sites and extravasate into these sites or form adjacent plasmacytomas to bone (167).

EMM cells upregulate the adhesion molecules platelet/ endothelial cell adhesion molecule-1 (PECAM-1), secreted protein and rich in cysteine (SPARC), and endoglin (ENG), illustrating the shift in adhesion specificity in EMM (170). EMM cells also upregulate nestin, an intermediate filament implicated in metastasis and invasion (171).

A mechanism for myeloma autocrine pro-survival loop lies in the co-expression of CD28 and its ligand CD86. Ligation of CD28 promotes cellular survival and drug resistance in HMCL, and silencing of CD28 and CD86 leads to respective increases in cell death $(88,89)$. Recent work from our lab has shown that CD86 can signal to confer survival and drug resistance in HMCL. CD86 overexpression induces molecular changes such as increased expression of integrin $B 1$ and $B 7$ and interferon regulatory factor 4 (IRF4), a transcription factor necessary for myeloma survival which directly targets $\operatorname{MYC}(89,172)$. Another autocrine loop involved in myeloma survival is secretion of HGF. HMCL and primary myeloma express the tyrosine kinase HGF receptor, c-Met, and produce HGF at variable levels. By this means, EMM cells can signal to stimulate c-Met thus preventing apoptosis and inducing proliferation through autocrine cytokine production $(173,174)$. Advances in screening technology using CRISPR offer new tools for future elucidation of genes necessary for HMCL survival and proliferation.

\section{Extramedullary Multiple Myeloma Angiogenesis Signaling}

One of the processes highly relied upon in the bone marrow microenvironment, angiogenesis, also has an important role in EMM. Hypoxia in the bone marrow causes myeloma cell upregulation of HIF1 $\alpha$ which regulates secretion of proangiogenic cytokines. HIF1 $\alpha$ is also upregulated in circulating plasma cells and is associated with myeloma EMT (175). Additional angiogenic factors are upregulated in EMM including VEGF, MMP-9, PECAM-1, and Ang-1. Other angiogenesis related genes such as PDGF, SPARC, NOTCH3, thrombospondin 2, TIMP3, and fibronectin 1 are overexpressed (162). Increased expression of these proteins indicates an important role for angiogenesis in EMM. Although current standard therapies for EMM such as lenalidomide (176) and bortezomib (140) are antiangiogenic, the role of angiogenesis in EMM remains largely unknown.

\section{Plasma Cell Leukemia Molecular Alterations}

PCL is an aggressive variant of EMM marked by rapidly proliferating circulating plasma cells and poor prognosis of patients. Primary immunoglobulin translocations are common in PCL with MAF translocations $[\mathrm{t}(14,16)$ and $\mathrm{t}(14,20)]$ being the most common followed by $\mathrm{t}(11,14)$ and $\mathrm{t}(4,14)$. Other common mutations in PCL are MYC translocations which can be found on $\operatorname{IgH}(5 \%), \operatorname{IgK}(10 \%)$, and $\operatorname{IgL}(10 \%)$ loci, respectively (177).

PCL also overexpresses certain genes compared to plasmacytomas including RPL17, CD14, TRAF2, TRAF3, and CCL2. Other affected cancer driver genes include those involved in cell-matrix adhesion and membrane organization (SPTB, CELA1), cell cycle and apoptosis (CIDEC), genome stability (KIF2B), and protein folding (CMYA5). PCL cells are also enriched in functional pathways including Cadherin/Wnt signaling, ECM-receptor, and G2/M cell cycle checkpoint. As PCL are circulating in the blood, there is a downregulation of integrins (CD11a, CD11c, CD29, CD49, CD49e) and other adhesion molecules (CD33, CD117, CD138, CD81) in comparison to EMM. PCL also expresses decreased markers of plasma cells (CD28, CD38) and increased markers of B cells (CD19, CD20, CD45) due to their high prevalence of $t(11,14)$ translocations $(177,178)$.

\section{CONCLUSION}

In the Game of Bones, myeloma cells are manipulators that identify allies within the bone marrow microenvironment to exploit and thereby enable their neutralization and evasion of their opposition, the host's immune defenses. Data that show microenvironment changes as early as MGUS propose that the microenvironment is susceptible to myeloma growth in precursor stages. Mutations in precursor stages beckon a "chicken or the egg" conundrum between myeloma cells and the microenvironment in assessing the advancement of this malignancy. By the time symptomatic myeloma develops, the Game of Bones has already tipped in favor of the cancer. This is because the disease is already quite evolved with numerous means of drug resistance and proliferation in its arsenal, and the cancer has a substantial advantage against innate defenses and chemotherapeutic intervention. In advanced stages, myeloma can readily proliferate in the bone marrow and develop the capacity to transcend the bone marrow.

Recent studies have aimed to tip the advantage back to the side of the host's defense system, either by effectively targeting myeloma cells and the microenvironment or by strengthening the immune response. As technology and detection tools improve, myeloma cells can be combatted at their early stages before treatment of myeloma or EMM is necessary. Modern genomic approaches such as single cell genomics, mass cytometry, ATAC-seq, whole genome bisulfite sequencing, and integrated phosphoproteomics can elucidate properly tailored treatments for improved efficacy and decreased toxicity of patients. The rise of IMiDs and targeted antibody treatments represent our growing understanding of the therapeutic role of targeting the microenvironment.

Mobilizing the body's own immune system also improves its odds at winning the Game of Bones. IMiDs, as well as CAR-T cell therapy are of particular interest as they can be utilized to bolster the body's defenses against its adversary. IMiDs are a potent frontline treatment for $\mathrm{MM}$, and have even been shown to improve patient outcome in the SMM stage (34). Overall, studies of the cancer biology in myeloma cells and their surrounding microenvironment using ex vivo patient studies, 
murine models, and HMCL provide insight to future treatment options and increased efficacy of therapy.

\section{AUTHOR CONTRIBUTIONS}

TK conceived and wrote the review. NJ, MD, and KL contributed to the writing and editing of manuscript.
LB conceived, edited, and oversaw the writing. All authors contributed to the article and approved the submitted version.

\section{FUNDING}

This work was supported by R01 CA121044 and R01 CA1192844.

\section{REFERENCES}

1. Myeloma - SEER Stat Fact Sheets. . http://seer.cancer.gov/statfacts/html/ mulmy.html.

2. Slifka MK, Ahmed R. Long-lived plasma cells: a mechanism for maintaining persistent antibody production. Curr Opin Immunol (1998) 10:252-8. doi: 10.1016/S0952-7915(98)80162-3

3. Dhodapkar MV. MGUS to myeloma: a mysterious gammopathy of underexplored significance. Blood (2016) 128:2599-606. doi: 10.1182/ blood-2016-09-692954

4. Bailur JK, McCachren SS, Doxie DB, Shrestha M, Pendleton KE, Nooka AK, et al. Early Alterations in Stem-Like/Resident T Cells, Innate and Myeloid Cells in the Bone Marrow in Preneoplastic Gammopathy. JCI Insight (2019) 5:1-10. doi: 10.1172/jci.insight. 127807

5. Hedvat CV, Comenzo RL, Teruya-Feldstein J, Olshen AB, Ely SA, Osman K, et al. Insights into extramedullary tumour cell growth revealed by expression profiling of human plasmacytomas and multiple myeloma. Br J Haematol (2003) 122:728-44. doi: 10.1046/j.1365-2141.2003.04481.x

6. Rajkumar SV, Dimopoulos MA, Palumbo A, Blade J, Merlini G, Mateos $\mathrm{MV}$, et al. International Myeloma Working Group updated criteria for the diagnosis of multiple myeloma. Lancet Oncol (2014) 15:e538-48. doi: 10. 1016/S1470-2045(14)70442-5

7. Larsen JT, Kumar SK, Dispenzieri A, Kyle RA, Katzmann JA, Rajkumar SV. Serum free light chain ratio as a biomarker for high-risk smoldering multiple myeloma. Leukemia (2013) 27:941-6. doi: 10.1038/leu.2012.296

8. Kastritis E, Terpos E, Moulopoulos L, Spyropoulou-Vlachou M, Kanellias N, Eleftherakis-Papaiakovou E, et al. Extensive bone marrow infiltration and abnormal free light chain ratio identifies patients with asymptomatic myeloma at high risk for progression to symptomatic disease. Leukemia (2013) 27:947-53. doi: 10.1038/leu.2012.309

9. Kastritis E, Moulopoulos LA, Terpos E, Koutoulidis V, Dimopoulos MA. The prognostic importance of the presence of more than one focal lesion in spine MRI of patients with asymptomatic (smoldering) multiple myeloma. Leukemia (2014) 28:2402-3. doi: 10.1038/leu.2014.230

10. Greipp PR, San Miguel J, Durie BGM, Crowley JJ, Barlogie B, Blade J, et al. International staging system for multiple myeloma. J Clin Oncol (2005) 23:3412-20. doi: 10.1200/JCO.2005.04.242

11. Palumbo A, Avet-Loiseau H, Oliva S, Lokhorst HM, Goldschmidt H, Rosinol L, et al. Revised International Staging System for Multiple Myeloma: A Report From International Myeloma Working Group. J Clin Oncol (2015) 33:2863-9. doi: 10.1200/JCO.2015.61.2267

12. Joseph NS, Kaufman JL, Dhodapkar MV, Hofmeister CC, Almaula DK, Heffner LT, et al. Long-Term Follow-Up Results of Lenalidomide, Bortezomib, and Dexamethasone Induction Therapy and Risk-Adapted Maintenance Approach in Newly Diagnosed Multiple Myeloma. J Clin Oncol (2020) 38:1928-37. doi: 10.1200/JCO.19.02515

13. Rajkumar SV. Multiple myeloma: 2020 update on diagnosis, risk-stratification and management. Am J Hematol (2020) 95:548-67. doi: 10.1002/ajh.25791

14. Schmidt TM, Barwick BG, Joseph NS, Heffner LT, Hofmeister CC, Bernal L, et al. Gain of Chromosome $1 \mathrm{q}$ is associated with early progression in multiple myeloma patients treated with lenalidomide, bortezomib, and dexamethasone. Blood Cancer J (2019) 9:1-13. doi: 10.1038/s41408-0190254-0

15. Greipp PR, Lust JA, O'Fallon WM, Katzmann JA, Witzig TE, Kyle RA. Plasma cell labeling index and beta 2-microglobulin predict survival

independent of thymidine kinase and C-reactive protein in multiple myeloma [see comments]. Blood (1993) 81:3382-7. doi: 10.1182/ blood.V81.12.3382.bloodjournal81123382

16. Lonial S, Boise LH, Kaufman J. How I treat high-risk myeloma. Blood (2015) 126:1536-43. doi: 10.1182/blood-2015-06-653261

17. Landgren O, Kyle RA, Pfeiffer RM, Katzmann JA, Caporaso NE, Hayes RB, et al. Monoclonal gammopathy of undetermined significance (MGUS) consistently precedes multiple myeloma: a prospective study. Blood (2009) 113:5412-7. doi: 10.1182/blood-2008-12-194241

18. Weiss BM, Abadie J, Verma P, Howard RS, Kuehl WM. A monoclonal gammopathy precedes multiple myeloma in most patients. Blood (2009) 113:5418-22. doi: 10.1182/blood-2008-12-195008

19. Waldenstrom J. Studies on conditions associated with disturbed gamma globulin formation (gammopathies). Harvey Lect (1960) 56:211-31.

20. Kyle RA. Monoclonal Gammopathy of Undetermined Significance. Natural History in 241 Cases. Am J Med (1978) 64:814-26. doi: 10.1016/0002-9343 (78)90563-6

21. Landgren O, Gridley G, Ingemar T, Caporaso NE, Goldin LR, Baris D, et al Risk of monoclonal gammopathy of undetermined significance (MGUS) and subsequent multiple myeloma among African American and white veterans in the United States. Blood (2006) 107:904-6. doi: 10.1182/blood-2005-083449

22. Landgren O, Kyle RA, Rajkumar SV. From Myeloma Precursor Disease to Multiple Myeloma: New Diagnostic Concepts and Opportunities for Early Intervention. Clin Cancer Res (2011) 17:1243-52. doi: 10.1158/10780432.CCR-10-1822

23. Kyle RA, Therneau TM, Rajkumar SV, Offord JR, Larson DR, Plevak MF, et al. A Long-Term Study of Prognosis in Monoclonal Gammopathy of Undetermined Significance. N Engl J Med (2002) 346:564-9. doi: 10.1056/ NEJMoa01133202

24. Kyle RA, Larson DR, Therneau TM, Dispenzieri A, Kumar S, Cerhan JR, et al. Long-Term Follow-up of Monoclonal Gammopathy of Undetermined Significance. N Engl J Med (2018) 378:241-9o. doi: 10.1056/NEJMoa1709974

25. Mills JR, Kohlhagen MC, Dasari S, Vanderboom PM, Kyle RA, Katzmann JA, et al. Comprehensive Assessment of M-Proteins Using Nanobody Enrichment Coupled to MALDI-TOF Mass Spectrometry. Clin Chem (2016) 62:1334-44. doi: 10.1373/clinchem.2015.253740

26. Zojer N, Ludwig H, Fiegl M, Stevenson FK, Sahota SS. Patterns of somatic mutations in $\mathrm{VH}$ genes reveal pathways of clonal transformation from MGUS to multiple myeloma. Blood (2003) 101:4137-9. doi: 10.1182/blood2002-09-2825

27. Barwick BG, Gupta VA, Vertino PM, Boise LH. Cell of Origin and Genetic Alterations in the Pathogenesis of Multiple Myeloma. Front Immunol (2019) 10:1121. doi: 10.3389/fimmu.2019.01121

28. Cohen AD, Raje N, Fowler JA, Mezzi K, Scott EC, Dhodapkar MV. How to Train Your T Cells: Overcoming Immune Dysfunction in Multiple Myeloma. Clin Cancer Res (2020) 26:1541-54. doi: 10.1158/10780432.CCR-19-2111

29. Kyle RA, Greipp PR. Smoldering multiple myeloma. N Engl J Med (1980) 302:1347-9. doi: 10.1056/NEJM198006123022405

30. Rajkumar SV, Landgren O, Mateos M-V. Smoldering multiple myeloma. Blood (2015) 125:3069-75. doi: 10.1182/blood-2014-09-568899

31. Lakshman A, Rajkumar SV, Buadi FK, Binder M, Gertz MA, Lacy MQ, et al Risk stratification of smoldering multiple myeloma incorporating revised 
IMWG diagnostic criteria. Blood Cancer J (2018) 8:1-10. doi: 10.1038/ s41408-018-0077-4

32. Neben K, Jauch A, Hielscher T, Hillengass J, Lehners N, Seckinger A, et al. Progression in Smoldering Myeloma Is Independently Determined by the Chromosomal Abnormalities del(17p), t(4;14), Gain 1q, Hyperdiploidy, and Tumor Load. J Clin Oncol (2013) 31:4325-32. doi: 10.1200/JCO.2012.48.4923

33. San Miguel J, Mateos MV, Gonzalez V, Dimopoulos MA, Kastritis E, Hajek R, et al. Updated risk stratification model for smoldering multiple myeloma (SMM) incorporating the revised IMWG diagnostic criteria. J Clin Oncol (2019) 37:8000-0. doi: 10.1200/JCO.2019.37.15_suppl.8000

34. Lonial S, Jacobus S, Fonseca R, Weiss M, Kumar S, Orlowski RZ, et al. Randomized Trial of Lenalidomide Versus Observation in Smoldering Multiple Myeloma. J Clin Oncol (2020) 38:1126-37. doi: 10.1200/ JCO. 19.01740

35. Weinstock M, Ghobrial IM. Extramedullary multiple myeloma. Leuk Lymphoma (2013) 54:1135-41. doi: 10.3109/10428194.2012.740562

36. Tsang RW, Campbell BA, Goda JS, Kelsey CR, Kirova YM, Parikh RR, et al. Radiation Therapy for Solitary Plasmacytoma and Multiple Myeloma: Guidelines From the International Lymphoma Radiation Oncology Group. Int J Radiat Oncol Biol Phys (2018) 101:794-808. doi: 10.1016/ j.ijrobp.2018.08.004

37. Touzeau C, Moreau P. How I treat extramedullary myeloma. Blood (2016) 127:971-6. doi: 10.1182/blood-2015-07-635383

38. Varettoni M, Corso A, Pica G, Mangiacavalli S, Pascutto C, Lazzarino M. Incidence, presenting features and outcome of extramedullary disease in multiple myeloma: a longitudinal study on 1003 consecutive patients. Ann Oncol (2010) 21:325-30. doi: 10.1093/annonc/mdp329

39. Bladé J, Fernandez de Larrea F, Rosinol L, Cibeira MT, Jimenez R, Powles R. Soft-tissue plasmacytomas in multiple myeloma: incidence, mechanisms of extramedullary spread, and treatment approach. J Clin Oncol (2011) 29:3805-12. doi: 10.1200/JCO.2011.34.9290

40. Fernández de Larrea C, Kyle RA, Durie BGM, Ludwig H, Usmani S, Vesole $\mathrm{DH}$, et al. Plasma cell leukemia: consensus statement on diagnostic requirements, response criteria and treatment recommendations by the International Myeloma Working Group. Leukemia (2013) 27:780-91. doi: 10.1038/leu.2012.336

41. Bink K, Haralambieva E, Kremer M, Ott G, Beham-Schmid C, de Leval L, et al. Primary extramedullary plasmacytoma: similarities with and differences from multiple myeloma revealed by interphase cytogenetics. Haematologica (2008) 93:623-6. doi: 10.3324/haematol.12005

42. Besse L, Sedlarikova L, Greslikova H, Kupska R, Almasi M, Penka M, et al. Cytogenetics in multiple myeloma patients progressing into extramedullary disease. Eur J Haematol (2016) 97:93-100. doi: 10.1111/ejh.12688

43. Dawson MA, Patil S, Spencer A. Extramedullary relapse of multiple myeloma associated with a shift in secretion from intact immunoglobulin to light chains. Haematologica (2007) 92:143-4. doi: 10.3324/ haematol.10297

44. Langley RR, Fidler IJ. The seed and soil hypothesis revisited - the role of tumor-stroma interactions in metastasis to different organs. Int J Cancer J Int Cancer (2011) 128:2527-35. doi: 10.1002/ijc.26031

45. Paget S. The Distribution of Secondary Growths in Cancer of the Breast. 1889. Cancer Metastasis Rev (1989) 8:98-101.

46. Das R, Strowig T, Verma R, Koduru S, Hafemann A, Hopf S, et al. Microenvironment-dependent growth of preneoplastic and malignant plasma cells in humanized mice. Nat Med (2016) 22:1351-7. doi: 10.1038/ nm.4202

47. Bergsagel PL, Kuehl WM, Zhan F, Sawyer J, Barlogie B, Shaughnessy J. Cyclin D dysregulation: an early and unifying pathogenic event in multiple myeloma. Blood (2005) 106:296-303. doi: 10.1182/blood-2005-01-0034

48. Bergsagel PL, Kuehl WM. Molecular pathogenesis and a consequent classification of multiple myeloma. J Clin Oncol (2005) 23:6333-8. doi: 10.1200/JCO.2005.05.021

49. Avet.-Loiseau H, Li JY, Facon T, Brigaudeau C, Morineau N, Maloisel F, et al. High Incidence of Translocations $\mathrm{t}(11 ; 14)(\mathrm{q} 13 ; \mathrm{q} 32)$ and $\mathrm{t}(4 ; 14)(\mathrm{p} 16 ; \mathrm{q} 32)$ in Patients With Plasma Cell Malignancies. Cancer Res (1998) 58:5640-5.

50. Shaughnessy J, Gabrea A, Qi Y, Brents L, Zhan F, Tian E, et al. Cyclin D3 at 6p21 Is Dysregulated by Recurrent Chromosomal Translocations to
Immunoglobulin Loci in Multiple Myeloma. Blood (2001) 98. doi: 10.1182/blood.V98.1.217

51. Hurt EM, Wiestner A, Rosenwald A, Shaffer AL, Campo E, Grogan T, et al. Overexpression of $\mathrm{c}$-maf is a frequent oncogenic event in multiple myeloma that promotes proliferation and pathological interactions with bone marrow stroma. Cancer Cell (2004) 5:191-9. doi: 10.1016/\$1535-6108(04)00019-4

52. Walker BA, Leone PE, Chiecchio L, Dickens NJ, Jenner MW, et al. A Compendium of Myeloma-Associated Chromosomal Copy Number Abnormalities and Their Prognostic Value. Blood (2010) 116:e56-65. doi: 10.1182/blood-2010-04-279596

53. Chiecchio L, Dagrada GP, Ibrahim AH, Cabanas ED, Protheroe RKM, Stockley DM, et al. Timing of Acquisition of Deletion 13 in Plasma Cell Dyscrasias Is Dependent on Genetic Context. Haematologica (2009) 94:1708-13. doi: 10.3324/haematol.2009.011064

54. Biner M, Rajkumar SV, Ketterling RP, Greipp PT, Dispenzieri A, Lacy MQ, et al. Prognostic Implications of Abnormalities of Chromosome 13 and the Presence of Multiple Cytogenetic High-Risk Abnormalities in Newly Diagnosed Multiple Myeloma. Blood Cancer J (2017) 7:e600. doi: 10.1038/ bcj. 2017.83

55. Chesi M, Stein CK, Garbitt VM, Sharik ME, Asmann YW, Bergsagel M, et al. Monosomic Loss of MIR15A/MIR16-1 Is a Driver of Multiple Myeloma Proliferation and Disease Progression. Blood Cancer Discov (2020) 1:1-14. doi: 10.1158/0008-5472.BCD-19-0068

56. Nobuyoshi M, Kawano M, Tanaka H, Ishikawa H, Tanabe O, Iwato K, et al. Increased Expression of the C-Myc Gene May Be Related to the Aggressive Transformation of Human Myeloma Cells. Br J Haematol (1991) 77:523-8. doi: 10.1111/j.1365-2141.1991.tb08620.x

57. Avet-Loiseau H, Gerson F, Magrangeas F, Minvielle S, Harousseau JL, Bataille R, et al. Rearrangements of the c-myc oncogene are present in $15 \%$ of primary human multiple myeloma tumors. Blood (2001) 98:3082-6. doi: 10.1182/blood.V98.10.3082

58. Barwick BG, Neri P, Bahlis NJ, Nooka AK, Dhodapkar MV, Jaye DL, et al. Multiple myeloma immunoglobulin lambda translocations portend poor prognosis. Nat Commun (2019) 10:1911. doi: 10.1038/s41467-01909555-6

59. Liu P, Leong T, Quam L, Billadeau D, Kay NE, Greipp P, et al. Activating Mutations of N- And K-ras in Multiple Myeloma Show Different Clinical Associations: Analysis of the Eastern Cooperative Oncology Group Phase III Trial. Blood (1996) 88:2699-706. doi: 10.1182/blood.V88.7.2699. bloodjournal8872699

60. Lin Y-HT, Way GP, Barwick BG, Mariano MC, Marcoulis M, Ferguson ID, et al. Integrated phosphoproteomics and transcriptional classifiers reveal hidden RAS signaling dynamics in multiple myeloma. Blood Adv (2019) 3:3214-27. doi: 10.1182/bloodadvances.2019000303

61. Chesi M, Brents LA, Ely SA, Bais C, Robbiani DF, Mesri EA, et al. Activated Fibroblast Growth Factor Receptor 3 Is an Oncogene That Contributes to Tumor Progression in Multiple Myeloma. Blood (2001) 97:729-36. doi: 10.1182/blood.V97.3.729

62. Andrulis M, Lehners N, Capper D, Penzel R, Heining C, Huellein J, et al. Targeting the BRAF V600E Mutation in Multiple Myeloma. Cancer Discov (2013) 3:862-9. doi: 10.1158/2159-8290.CD-13-0014

63. Maura F, Rustad EH, Yellapantula V, Luksza M, Hoyos D, Maclachlan KH, et al. Role of AID in the temporal pattern of acquisition of driver mutations in multiple myeloma. Leukemia (2020) 34:1476-80. doi: 10.1038/s41375019-0689-0

64. Koduru S, Wong E, Strowig T, Sundaram R, Zhang L, Strout MP, et al. Dendritic cell-mediated activation-induced cytidine deaminase (AID)dependent induction of genomic instability in human myeloma. Blood (2012) 119:2302-9. doi: 10.1182/blood-2011-08-376236

65. Menu E, Asosingh K, Indraccolo S, De Raeve H, Van Riet I, Van Valckenborgh E, et al. The involvement of stromal derived factor 1alpha in homing and progression of multiple myeloma in the 5TMM model. Haematologica (2006) 91:605-12. doi: 10.3324/\%25x

66. Damiano JS, Cress AE, Hazlehurst LA, Shtil AA, Dalton WS. Cell adhesion mediated drug resistance (CAM-DR): role of integrins and resistance to apoptosis in human myeloma cell lines. Blood (1999) 93:1658-67. doi: 10.1182/blood.V93.5.1658 
67. Katz B-Z. Adhesion molecules-The lifelines of multiple myeloma cells. Semin Cancer Biol (2010) 20:186-95. doi: 10.1016/j.semcancer.2010.04.003

68. Hosen N. Integrins in multiple myeloma. Inflamm Regen (2020) 40:4. doi: 10.1186/s41232-020-00113-y

69. Damiano JS. \& Dalton W.S. Integrin-mediated Drug Resistance in Multiple Myeloma. Leuk Lymphoma (2000) 38:1658-67. doi: 10.3109/ 10428190009060320

70. Neri P, Ren L, Azab AK, Brentnall M, Gratton K, Klimowicz AC, et al. Integrin $\beta 7$-mediated regulation of multiple myeloma cell adhesion, migration, and invasion. Blood (2011) 117:6202-13. doi: 10.1182/blood2010-06-292243

71. Landowski TH, Olashaw NE, Agrawal D, Dalton WS. Cell adhesionmediated drug resistance (CAM-DR) is associated with activation of NFkappa B (RelB/p50) in myeloma cells. Oncogene (2003) 22:2417-21. doi: 10.1038/sj.onc. 1206315

72. Hosen N, Matsunaga Y, Hasegawa K, Matsuno H, Nakamura Y, Makita M, et al. The activated conformation of integrin $\beta 7$ is a novel multiple myeloma-specific target for CAR T cell therapy. Nat Med (2017) 23:143643. doi: $10.1038 / \mathrm{nm} .4431$

73. Riet IV, Waele MD, Remels L, Lacor P, Schots R, Camp BV, et al. Expression of cytoadhesion molecules (CD56, CD54, CD18 and CD29) by myeloma plasma cells. Br J Haematol (1991) 79:421-7. doi: 10.1111/j.13652141.1991.tb08050.x

74. Hideshima T, Mitsiades C, Tonon G, Richardson PG, Anderson KC. Understanding multiple myeloma pathogenesis in the bone marrow to identify new therapeutic targets. Nat Rev Cancer (2007) 7:585-98. doi: $10.1038 /$ nrc2 189

75. Sanderson RD, Turnbull JE, Gallagher JT, Lander AD. Fine structure of heparan sulfate regulates syndecan-1 function and cell behavior. J Biol Chem (1994) 269:13100-6. doi: 10.1016/S0021-9258(17)36804-7

76. Reijmers RM, Groen RWJ, Rozemuller H, Kuil A, de Haan-Kramer A, Csikos T, et al. Targeting EXT1 Reveals a Crucial Role for Heparan Sulfate in the Growth of Multiple Myeloma. Blood (2010) 115:601-4. doi: 10.1182/ blood-2009-02-204396

77. Levy-Adam F, Feld S, Suss-Toby E, Vlodavsky I, Ilan N. Heparanase Facilitates Cell Adhesion and Spreading by Clustering of Cell Surface Heparan Sulfate Proteoglycans. PLoS One (2008) 3:e2319. doi: 10.1371/ journal.pone.0002319

78. Yang Y, Macleod V, Miao MQ, Theus A, Zhan F, Shaughnessy JD, et al. Heparanase enhances syndecan-1 shedding: a novel mechanism for stimulation of tumor growth and metastasis. J Biol Chem (2007) 282:13326-33. doi: 10.1074/jbc.M611259200

79. Yang Y, Yaccoboy S, Liu W, Langford JK, Pumphrey CY, Theus A, et al. Soluble syndecan-1 promotes growth of myeloma tumors in vivo. Blood (2002) 100:610-7. doi: 10.1182/blood.V100.2.610

80. van de Donk NWCJ, Usmani SZ. CD38 Antibodies in Multiple Myeloma: Mechanisms of Action and Modes of Resistance. Front Immunol (2018) 9:2134. doi: 10.3389/fimmu.2018.02134

81. Ahsmann EJ, Lokhorst HM, Dekker AW, Bloem AC. Lymphocyte functionassociated antigen-1 expression on plasma cells correlates with tumor growth in multiple myeloma. Blood (1992) 79:2068-75. doi: 10.1182/ blood.V79.8.2068.bloodjournal7982068

82. Asosingh K, Vankerkhove V, Van Riet I, Van Camp B, Vanderkerken K. Selective in vivo growth of lymphocyte function- associated antigen-1positive murine myeloma cells. Involvement of function-associated antigen-1-mediated homotypic cell-cell adhesion. Exp Hematol (2003) 31:48-55. doi: 10.1016/S0301-472X(02)00970-0

83. Tagde A, Rajabi H, Bouillez A, Alam M, Gali R, Bailey S, et al. MUC1-C drives MYC in multiple myeloma. Blood (2016) 127:2587-97. doi: 10.1182/ blood-2015-07-659151

84. Linsley PS, Brady W, Grosmaire L, Aruffo A, Damle NK, Ledbetter JA. Binding of the $\mathrm{B}$ cell activation antigen $\mathrm{B} 7$ to $\mathrm{CD} 28$ costimulates $\mathrm{T}$ cell proliferation and interleukin 2 mRNA accumulation. J Exp Med (1991) 173:721-30. doi: 10.1084/jem.173.3.721

85. Bahlis NJ, King AM, Kolonias D, Carlson LM, Liu HY, Hussein MA, et al. CD28-mediated regulation of multiple myeloma cell proliferation and survival. Blood (2007) 109:5002-10. doi: 10.1182/blood-2006-03012542
86. Rozanski CH, Arens R, Carlson LM, Nair JR, Boise LH, Chanan-Khan AA, et al. Sustained antibody responses depend on CD28 function in bone marrow-resident plasma cells. J Exp Med (2011) 208:1435-46. doi: 10.1084/ jem.20110040

87. Rozanski CH, Utley A, Carlson LM, Farren MR, Murray M, Russell LM, et al. CD28 Promotes Plasma Cell Survival, Sustained Antibody Responses, and BLIMP-1 Upregulation through Its Distal PYAP Proline Motif. J Immunol Baltim Md 1950 (2015) 194:4717-28. doi: 10.4049/jimmunol.1402260

88. Murray ME, Gavile CM, Nair JR, Koorella C, Carlson LM, Buac D, et al. CD28-mediated pro-survival signaling induces chemotherapeutic resistance in multiple myeloma. Blood (2014) 123:3770-9. doi: 10.1182/blood-2013-10530964

89. Gavile CM, Barwick BG, Newman S, Neri P, Nooka AK, Lonial S, et al. CD86 regulates myeloma cell survival. Blood Adv (2017) 1:2307-19. doi: 10.1182/ bloodadvances.2017011601

90. Hideshima T, Nakamura N, Chauhan D, Anderson KC. Biologic sequelae of interleukin-6 induced PI3-K/Akt signaling in multiple myeloma. Oncogene (2001) 20:5991-6000. doi: 10.1038/sj.onc. 1204833

91. Chauhan D, Uchiyama H, Akbarali Y, Urashima M, Yamamoto, Libermann TA, et al. Multiple myeloma cell adhesion-induced interleukin- 6 expression in bone marrow stromal cells involves activation of NF-kappa B. Blood (1996) 87:110412. doi: 10.1182/blood.V87.3.1104.bloodjournal8731104

92. Uchiyama H, Barut BA, Mohrbacher AF, Chauhan D, Anderson KC. Adhesion of human myeloma-derived cell lines to bone marrow stromal cells stimulates interleukin-6 secretion. Blood (1993) 82:3712-20. doi: 10.1182/blood.V82.12.3712.bloodjournal82123712

93. Gupta VA, Matulis SM, Conage-Pough JE, Nooka AK, Kaufman JL, Lonial S, et al. Bone marrow microenvironment-derived signals induce Mcl-1 dependence in multiple myeloma. Blood (2017) 129:1969-79. doi: 10.1182/ blood-2016-10-745059

94. Conage-Pough JE. \& Boise L.H. Phosphorylation Alters Bim-mediated Mcl1 Stabilization and Priming. FEBS J (2018) 285:2626-40. doi: 10.1111/febs. 14505

95. Moreaux J, Legouffe E, Jourdan E, Quittet P, Reme T, Lugagne C, et al. BAFF and APRIL protect myeloma cells from apoptosis induced by interleukin 6 deprivation and dexamethasone. Blood (2004) 103:3148-57. doi: 10.1182/ blood-2003-06-1984

96. Schneider P, MacKay F, Steiner V, Hofman K, Bodmer JL, Holler N, et al. BAFF, a novel ligand of the tumor necrosis factor family, stimulates B cell growth. J Exp Med (1999) 189:1747-56. doi: 10.1084/jem.189.11.1747

97. Novak AJ, Darce JR, Arendt BK, Harder B, Henderson K, Kindsvogel W, et al. Expression of BCMA, TACI, and BAFF-R in multiple myeloma: a mechanism for growth and survival. Blood (2004) 103:689-94. doi: 10.1182/ blood-2003-06-2043

98. Tai Y-T, Acharya C, An G, Moschetta M, Zhong MY, Feng X, et al. APRIL and BCMA promote human multiple myeloma growth and immunosuppression in the bone marrow microenvironment. Blood (2016) 127:3225-36. doi: 10.1182/blood-2016-01-691162

99. Timmers M, Roex G, Wang Y, Campillo-Davo D, Van Tendeloo VFI, Chu Y, et al. Chimeric Antigen Receptor-Modified T Cell Therapy in Multiple Myeloma: Beyond B Cell Maturation Antigen. Front Immunol (2019) 10:1613. doi: 10.3389/fimmu.2019.01613

100. Kukreja A, Hutchinson A, Dhodapkar A, Mazumder A, Vesole D, Angitapalli R, et al. Enhancement of clonogenicity of human multiple myeloma by dendritic cells. J Exp Med (2006) 203:1859-65. doi: 10.1084/ jem.20052136

101. Hideshima T, Chauhan D, Schlossman R, Richardson P, Anderson KC. The role of tumor necrosis factor alpha in the pathophysiology of human multiple myeloma: therapeutic applications. Oncogene (2001) 20:4519-27. doi: 10.1038/si.onc. 1204623

102. Singhal S, Mehta J, Desikan R, Ayers D, Roberson P, Munshi N, et al. Antitumor Activity of Thalidomide in Refractory Multiple Myeloma. N Engl J Med (1999) 341:1565-71. doi: 10.1056/NEJM199911183412102

103. Mitsiades CS, Mitsiades NS, McMullan CJ, Poulaki V, Shringarpur R, Akiyama M, et al. Inhibition of the insulin-like growth factor receptor-1 tyrosine kinase activity as a therapeutic strategy for multiple myeloma, other hematologic malignancies, and solid tumors. Cancer Cell (2004) 5:221-30. doi: 10.1016/S1535-6108(04)00050-9 
104. Choi SJ, Oba Y, Gazitt Y, Alsina M, Cruz J, Anderson J, et al. Antisense inhibition of macrophage inflammatory protein 1-alpha blocks bone destruction in a model of myeloma bone disease. J Clin Invest (2001) 108:1833-41. doi: 10.1172/JCI200113116

105. Abe M, Hiura K, Wilde J, Moriyama K, Hashimoto T, Ozaki S, et al. Role for Macrophage Inflammatory Protein (MIP)-1alpha and MIP-1beta in the Development of Osteolytic Lesions in Multiple Myeloma. Blood (2002) 100:2195-202. doi: 10.1182/blood.V100.6.2195.h81802002195_2195_2202

106. Oba Y, Lee JW, Ehrlich LA, Chung HY, Jelinek DF, Callander NS, et al. MIP1alpha Utilizes Both CCR1 and CCR5 to Induce Osteoclast Formation and Increase Adhesion of Myeloma Cells to Marrow Stromal Cells. Exp Hematol (2005) 33:272-8. doi: 10.1016/j.exphem.2004.11.015

107. Han JH, Choi SJ, Kurihara N, Koide M, Oba Y, Roodman GD. Macrophage Inflammatory protein-1alpha Is an Osteoclastogenic Factor in Myeloma That Is Independent of Receptor Activator of Nuclear Factor kappaB Ligand. Blood (2001) 97:3349-53. doi: 10.1182/blood.V97.11.3349

108. Yin L. Chondroitin synthase 1 is a key molecule in myeloma cell-osteoclast interactions. J Biol Chem (2005) 280:15666-72. doi: 10.1074/jbc.M409877200

109. Colombo M, Mirandola L, Platonova N, Apicella L, Basile A, Figueroa AJ, et al. Notch-directed microenvironment reprogramming in myeloma: a single path to multiple outcomes. Leukemia (2013) 27:1009-18. doi: 10.1038/leu.2013.6

110. Delgado-Calle J, Anderson J, Cregor MD, Hiasa M, Chirgwin JM, Carlesso N, et al. Bidirectional Notch Signaling and Osteocyte-Derived Factors in the Bone Marrow Microenvironment Promote Tumor Cell Proliferation and Bone Destruction in Multiple Myeloma. Cancer Res (2016) 76:1089-100. doi: 10.1158/0008-5472.CAN-15-1703

111. Michigami T, Shimizu M, Williams PJ, Niewolna M, Dallas SL, Mundy GR, et al. Cell-cell contact between marrow stromal cells and myeloma cells via VCAM-1 and alpha(4)beta(1)-integrin enhances production of osteoclaststimulating activity. Blood (2000) 96:1953-60. doi: 10.1182/ blood.V96.5.1953.h8001953_1953_1960

112. Pearse RN, Sordillo EM, Yaccoby S, Wong BR, Liau DF, Colman N, et al. Multiple Myeloma Disrupts the TRANCE/ Osteoprotegerin Cytokine Axis to Trigger Bone Destruction and Promote Tumor Progression. Proc Natl Acad Sci U S A (2001) 98:11581-6. doi: 10.1073/pnas.201394498

113. Nguyen AN, Stebbins EG, Henson M, O’Young G, Choi SJ, Quon D, et al. Normalizing the bone marrow microenvironment with p38 inhibitor reduces multiple myeloma cell proliferation and adhesion and suppresses osteoclast formation. Exp Cell Res (2006) 312:1909-23. doi: 10.1016/j.yexcr.2006.02.026

114. Terpos E, Ntanasis-Stathopoulos I, Gavriatopoulou M, Dimopoulos MA. Pathogenesis of bone disease in multiple myeloma: from bench to bedside. Blood Cancer J (2018) 8:1-12. doi: 10.1038/s41408-017-0037-4

115. Saeki Y, Mima T, Ishii T, Ogata A, Kobayashi H, Ohshima S, et al. Enhanced production of osteopontin in multiple myeloma: clinical and pathogenic implications. Br J Haematol (2003) 123:263-70. doi: 10.1046/j.13652141.2003.04589.x

116. Noonan K, Marchionni L, Anderson J, Pardoll D, Roodman GD, Borrello I. A novel role of IL-17-producing lymphocytes in mediating lytic bone disease in multiple myeloma. Blood (2010) 116:3554-63. doi: 10.1182/blood-201005-283895

117. Terpos E, Dimopoulos M-A. Myeloma bone disease: pathophysiology and management. Ann Oncol (2005) 16:1223-31. doi: 10.1093/annonc/ mdi235

118. Croucher PII, Shiman CM, Lippitt J, Perry M, Asosingh K, Hijzen A, et al. Osteoprotegerin inhibits the development of osteolytic bone disease in multiple myeloma. Blood (2001) 98:3534-40. doi: 10.1182/blood.V98.13.3534

119. Boyle WJ, Simonet WS, Lacey DL. Osteoclast differentiation and activation. Nature (2003) 423:337-42. doi: 10.1038/nature01658

120. Terpos E, Szydlo R, Apperley JF, Hatjiharissi E, Politou M, Meletis J, et al. Soluble receptor activator of nuclear factor kappaB ligand-osteoprotegerin ratio predicts survival in multiple myeloma: proposal for a novel prognostic index. Blood (2003) 102:1064-9. doi: 10.1182/blood-2003-02-0380

121. Giuliani N, Bataille R, Mancini C, Lazzaretti M, Barillé S. Myeloma cells induce imbalance in the osteoprotegerin/osteoprotegerin ligand system in the human bone marrow environment. Blood (2001) 98:3527-33. doi: 10.1182/blood.V98.13.3527

122. Sugatani T, Alvarez UM, Hruska KA. Activin A stimulates IkappaB-alpha/ NFkappaB and RANK expression for osteoclast differentiation, but not AKT survival pathway in osteoclast precursors. J Cell Biochem (2003) 90:59-67. doi: $10.1002 / j \mathrm{cb} .10613$

123. Colucci S, Brunetti G, Oranger A, Mori G, Sardone F, Specchia G, et al. Myeloma cells suppress osteoblasts through sclerostin secretion. Blood Cancer J (2011) 1:e27-7. doi: 10.1038/bcj.2011.22

124. Khoo WH, Ledergor G, Weiner A, Roden DL, Terry RL, McDonald MM, et al. A niche-dependent myeloid transcriptome signature defines dormant myeloma cells. Blood (2019) 134:30-43. doi: 10.1182/blood 2018880930

125. Terpos E, Kastritis E, Christoulas D, Gkotzamanidou M, EleutherakisPapaiakovou E, Kanellias N, et al. Circulating activin-A is elevated in patients with advanced multiple myeloma and correlates with extensive bone involvement and inferior survival; no alterations post-lenalidomide and dexamethasone therapy. Ann Oncol (2012) 23:2681-86. doi: 10.1093/ annonc/mds068

126. Lee JW, Chung HY, Ehrlich LA, Jelinek DF, Callander NS, Roodman GD, et al. IL-3 expression by myeloma cells increases both osteoclast formation and growth of myeloma cells. Blood (2004) 103:2308-15. doi: 10.1182/blood2003-06-1992

127. Giuliani N, Colla S, Morandi F, Lazzaretti M, Sala R, Bonomini S, et al. Myeloma cells block RUNX2/CBFA1 activity in human bone marrow osteoblast progenitors and inhibit osteoblast formation and differentiation. Blood (2005) 106:2472-83. doi: 10.1182/blood-2004-12-4986

128. Terpos E, Dimopoulos MA. Interaction between the skeletal and immune systems in cancer: mechanisms and clinical implications. Cancer Immunol Immunother CII (2011) 60:305-17. doi: 10.1007/s00262-011-0974-x

129. Oshima T, Abe M, Asano J, Hara T, Kitazoe K, Sekimoto E, et al. Myeloma cells suppress bone formation by secreting a soluble Wnt inhibitor, sFRP-2. Blood (2005) 106:3160-5. doi: 10.1182/blood-2004-12-4940

130. Yaccoby S, Ling W, Zhan F, Walker R, Barlogie B, Shaughnessy JD. Antibody-based inhibition of DKK1 suppresses tumor-induced bone resorption and multiple myeloma growth in vivo. Blood (2007) 109:210611. doi: 10.1182/blood-2006-09-047712

131. Ehrlich LA, Chung HY, Ghobrial I, Choi SJ, Morandi F, Colla S, et al. IL-3 Is a Potential Inhibitor of Osteoblast Differentiation in Multiple Myeloma. Blood (2005) 106:1407-14. doi: 10.1182/blood-2005-03-1080

132. Rajkumar SV, Mesa RA, Fonseca R, Schroeder G, Plevak MF, Dispenzieri A, et al. Bone marrow angiogenesis in 400 patients with monoclonal gammopathy of undetermined significance, multiple myeloma, and primary amyloidosis. Clin Cancer Res (2002) 8:2210-6.

133. Bhaskar A, Tiwary BN. Hypoxia inducible factor-1 alpha and multiple myeloma. Int J Adv Res (2016) 4:706-15.

134. Vacca A, Di Loreto M, Ribatti D, Di Stefano R, Gadaleta-Caldarola G, Iodice G, et al. Bone marrow of patients with active multiple myeloma: angiogenesis and plasma cell adhesion molecules LFA-1, VLA-4, LAM-1, and CD44. Am J Hematol (1995) 50:9-14. doi: 10.1002/ajh.2830500103

135. Andersen NF, Standal T, Nielsen JL, Heickendorff L, Borset M, Sorensen FB, et al. Syndecan-1 and angiogenic cytokines in multiple myeloma: correlation with bone marrow angiogenesis and survival. Br J Haematol (2005) 128:2107. doi: 10.1111/j.1365-2141.2004.05299.x

136. Derksen PWB, Keehnen RMJ, Evers LM, van Oers MHL, Spaargaren M, Pals ST. Cell surface proteoglycan syndecan-1 mediates hepatocyte growth factor binding and promotes Met signaling in multiple myeloma. Blood (2002) 99:1405-10. doi: 10.1182/blood.V99.4.1405

137. Vande Broek I, Asosingh K, Allegaert V, Leleu X, Facon T, Vanderkerken K, et al. Bone marrow endothelial cells increase the invasiveness of human multiple myeloma cells through upregulation of MMP-9: evidence for a role of hepatocyte growth factor. Leukemia (2004) 18:976-82. doi: 10.1038/ s.leu. 2403331

138. Purushothaman A, Uyama T, Kobayashi F, Yamada S, Sugahara K, Rapraeger AC, et al. Heparanase-enhanced Shedding of syndecan-1 by Myeloma Cells Promotes Endothelial Invasion and Angiogenesis. Blood (2010) 115:2449-57. doi: 10.1182/blood-2009-07-234757

139. Vacca A, Ribatti D, Presta M, Iurlaro M, Ria R, Albini A, et al. Bone Marrow Neovascularization, Plasma Cell Angiogenic Potential, and Matrix metalloproteinase-2 Secretion Parallel Progression of Human Multiple Myeloma. Blood (1999) 93:3064-73. doi: 10.1182/blood.V93.9.3064. 409k07_3064_3073 
140. Roccaro AM, Hideshima T, Raje N, Kumar S, Ishitsuka K, Yasui H, et al. Bortezomib Mediates Antiangiogenesis in Multiple Myeloma via Direct and Indirect Effects on Endothelial Cells. Cancer Res (2006) 66:184-91. doi: 10.1158/0008-5472.CAN-05-1195

141. Dhodapkar MV, Krasovsky J, Olson K. T cells from the tumor microenvironment of patients with progressive myeloma can generate strong, tumor-specific cytolytic responses to autologous, tumor-loaded dendritic cells. Proc Natl Acad Sci (2002) 99:13009-13. doi: 10.1073/ pnas.202491499

142. Feyler S, von Lilienfeld-Toal M, Jarmin S, Marles L, Rawstron A, Ashcroft AJ, et al. CD4(+)CD25(+)FoxP3(+) regulatory T cells are increased whilst CD3 $(+) \mathrm{CD} 4(-) \mathrm{CD} 8(-)$ alphabetaTCR(+) Double Negative T cells are decreased in the peripheral blood of patients with multiple myeloma which correlates with disease burden. Br J Haematol (2009) 144:686-95. doi: 10.1111/j.13652141.2008.07530.x

143. Nair JR, Carlson LM, Koorella C, Rozanski CH, Byrne GE, Bergsagel LP, et al. CD28 expressed on malignant plasma cells induces a prosurvival and immunosuppressive microenvironment. J Immunol Baltim Md 1950 (2011) 187:1243-53. doi: 10.4049/jimmunol.1100016

144. Koorella C, Nair JR, Murray ME, Carlson LM, Watkins SK, Lee KP. Novel regulation of $\mathrm{CD} 80 / \mathrm{CD} 86$-induced phosphatidylinositol 3-kinase signaling by NOTCH1 protein in interleukin-6 and indoleamine 2,3-dioxygenase production by dendritic cells. J Biol Chem (2014) 289:7747-62. doi: 10.1074/jbc.M113.519686

145. Leone P, Di Lernia G, Solimando AG, Cicco S, Saltarella I, Lamanuzzi A, et al. Bone marrow endothelial cells sustain a tumor-specific CD8+ T cell subset with suppressive function in myeloma patients. Oncoimmunology (2019) 8:e1486949. doi: 10.1080/2162402X.2018.1486949

146. Mouhieddine TH, Weeks LD, Ghobrial IM. Monoclonal gammopathy of undetermined significance. Blood (2019) 133:2484-94. doi: 10.1182/ blood.2019846782

147. De Veirman K, Menu E, Maes K, De Beule N, De Smedt E, Maes A, et al. Myeloid-derived suppressor cells induce multiple myeloma cell survival by activating the AMPK pathway. Cancer Lett (2019) 442:233-41. doi: 10.1016/ j.canlet.2018.11.002

148. De Veirman K, Van Ginderachter JA, Lub S, De Beule N, Thielemans K, Bautmans I, et al. Multiple myeloma induces Mcl-1 expression and survival of myeloid-derived suppressor cells. Oncotarget (2015) 6:10532-47. doi: 10.18632/ oncotarget. 3300

149. Bi E, Li R, Bover LC, Li H, Su P, Ma X, et al. E-cadherin expression on multiple myeloma cells activates tumor-promoting properties in plasmacytoid DCs. J Clin Invest (2018) 128:4821-31. doi: 10.1172/JCI121421

150. El-Sherbiny YM, Meade JL, Holmes TD, McGonagle D, Mackie SL, Morgan AW, et al. The Requirement for DNAM-1, NKG2D, and NKp46 in the Natural Killer Cell-Mediated Killing of Myeloma Cells. Cancer Res (2007) 67:8444-9. doi: 10.1158/0008-5472.CAN-06-4230

151. Görgün G, Samur MK, Cowens KB, Paula S, Bianchi G, Anderson JE, et al. Lenalidomide Enhances Immune Checkpoint Blockade-Induced Immune Response in Multiple Myeloma. Clin Cancer Res (2015) 21:4607-18. doi: 10.1158/1078-0432.CCR-15-0200

152. Pazina T, James AM, MacFarlane AW, Bezman NA, Henning KA, Bee C, et al. The anti-SLAMF7 antibody elotuzumab mediates NK cell activation through both CD16-dependent and -independent mechanisms. Oncoimmunology (2017) 6:e1339853. doi: 10.1080/2162402X.2017.1339853

153. Krejcik J, Casneuf T, Nijhof IS, Verbist B, Bald J, Plesner T, et al. Daratumumab depletes CD38+ immune regulatory cells, promotes T-cell expansion, and skews T-cell repertoire in multiple myeloma. Blood (2016) 128:384-94. doi: 10.1182/blood-2015-12-687749

154. Viola D, Dona A, Caserta E, Troadec E, Besi F, McDonald T, et al. Daratumumab induces mechanisms of immune activation through CD38+ NKcell targeting. Leukemia (2020) 35:1-12. doi: 10.1038/s41375-020-0810-4

155. Witzig TE, Laumann KM, Lacy MQ, Hayman SR, Dispenzieri A, Kumar S, et al. A Phase III Randomized Trial of Thalidomide Plus Zoledronic Acid Versus Zoledronic Acid Alone in Patients With Asymptomatic Multiple Myeloma. Leukemia (2013) 27:220-5. doi: 10.1038/leu.2012.236

156. Mateos MV, Hernandez MT, Giraldo P, de la Rubia J, de Arriba F, Corral LL, et al. Lenalidomide Plus Dexamethasone for High-Risk Smoldering Multiple Myeloma. N Engl J Med (2013) 369:438-47. doi: 10.1056/NEJMoa1300439
157. Korde N, Zingone A, Kwok M, Manasanch EE, Bhutani M, Costello R, et al. Phase II clinical and correlative study of carfilzomib, lenalidomide, and dexamethasone (CRd) in newly diagnosed multiple myeloma (MM) patients. J Clin Oncol (2012) 30:e18568-8. doi: 10.1200/jco.2012.30.15_suppl.e18568

158. Lonial S, Jacobus SJ, Weiss M, Kumar S, Orlowski RZ, Kaufman JL, et al. E3A06: Randomized phase III trial of lenalidomide versus observation alone in patients with asymptomatic high-risk smoldering multiple myeloma. J Clin Oncol (2019) 37:8001-1. doi: 10.1200/JCO.2019.37.15_ suppl.8001

159. Kumar S, Rajkumar SV, Kyle RA, Lacy MQ, Dispenzieri A, Fonseca R, et al. Prognostic value of circulating plasma cells in monoclonal gammopathy of undetermined significance. J Clin Oncol (2005) 23:5668-74. doi: 10.1200/ JCO.2005.03.159

160. Butcher EC, Picker LJ. Lymphocyte homing and homeostasis. Science (1996) 272:60-6. doi: 10.1126/science.272.5258.60

161. Vande Broek I, Leleu X, Schots R, Facon T, Vanderkerken K, Van Camp B, et al. Clinical significance of chemokine receptor (CCR1, CCR2 and CXCR4) expression in human myeloma cells: the association with disease activity and survival. Haematologica (2006) 91:200-6.

162. Bhutani M, Foureau DM, Atrash S, Voorhees PM, Usmani SZ. Extramedullary multiple myeloma. Leukemia (2020) 34:1-20. doi: 10.1038/s41375-019-0660-0

163. Dahl IMS, Rasmussen T, Kauric G, Husebekk A. Differential expression of CD56 and CD44 in the evolution of extramedullary myeloma. Br J Haematol (2002) 116:273-7. doi: 10.1046/j.1365-2141.2002.03258.x

164. Azab AK, Quang P, Azab F, Pitsillides C, Thompson B, Chonghaile T, et al. $\mathrm{P}$-selectin glycoprotein ligand regulates the interaction of multiple myeloma cells with the bone marrow microenvironment. Blood (2012) 119:1468-78. doi: 10.1182/blood-2011-07-368050

165. Wang S-Y, Hao HL, Deng K, Li Y, Cheng ZY, Chao LV, et al. Expression levels of phosphatase and tensin homolog deleted on chromosome 10 (PTEN) and focal adhesion kinase in patients with multiple myeloma and their relationship to clinical stage and extramedullary infiltration. Leuk Lymphoma (2012) 53:1162-8. doi: 10.3109/10428194.2011.647311

166. Tohami T, Drucker L, Shapiro H, Radnay J, Lishner M. Overexpression of Tetraspanins Affects Multiple Myeloma Cell Survival and Invasive Potential. FASEB J (2007) 21:691-9. doi: 10.1096/fj.06-6610com

167. Broek IV, Vanderkerken K, Camp BV, Riet IV. Extravasation and homing mechanisms in multiple myeloma. Clin Exp Metastasis (2008) 25:325-34. doi: 10.1007/s10585-007-9108-4

168. Li J, Pan Q, Rowan PD, Trotter TN, Peker D, Regal KM, et al. Heparanase promotes myeloma progression by inducing mesenchymal features and motility of myeloma cells. Oncotarget (2016) 7:11299-309. doi: 10.18632/ oncotarget.7170

169. Morgan GJ, Walker BA, Davies FE. The genetic architecture of multiple myeloma. Nat Rev Cancer (2012) 12:335-48. doi: 10.1038/nrc3257

170. Jelinek T, Bezdekova R, Zatopkova M, Burgos L, Simicek M, Sevcikova T, et al. Current applications of multiparameter flow cytometry in plasma cell disorders. Blood Cancer J (2017) 7:e617. doi: 10.1038/bcj.2017.90

171. Matsuda Y, Naito Z, Kawahara K, Nakazawa N, Korc M, Ishiwata T. Nestin is a novel target for suppressing pancreatic cancer cell migration, invasion and metastasis. Cancer Biol Ther (2011) 11:512-23. doi: 10.4161/ cbt.11.5.14673

172. Shaffer AL, Emre NCT, Lamy L, Ngo VN, Wright G, Xiao W, et al. IRF4 addiction in multiple myeloma. Nature (2008) 454:226-31. doi: 10.1038/ nature 07064

173. Børset M, Lien E, Espevik T, Helseth E, Waage A, Sundan A. Concomitant Expression of Hepatocyte Growth Factor/Scatter Factor and the Receptor cMET in Human Myeloma Cell Lines. J Biol Chem (1996) 271:24655-61. doi: $10.1074 / \mathrm{jbc} .271 .40 .24655$

174. Derksen PWB, de Gorter DJJ, Meijer HP, Bende RJ, van Dijk M, Lokhorst $\mathrm{HM}$, et al. The hepatocyte growth factor/Met pathway controls proliferation and apoptosis in multiple myeloma. Leukemia (2003) 17:764-74. doi: $10.1038 /$ sj.leu.2402875

175. Azab AK, Hu J, Quang P, Azab F, Pitsillides C, Awwad R, et al. Hypoxia promotes dissemination of multiple myeloma through acquisition of epithelial to mesenchymal transition-like features. Blood (2012) 119:578294. doi: 10.1182/blood-2011-09-380410 
176. Dimopoulos M, Spencer A, Attal M, Prince HM, Harousseau JL, Dmoszynska A, et al. Lenalidomide plus dexamethasone for relapsed or refractory multiple myeloma. N Engl J Med (2007) 357:2123-32. doi: 10.1056/NEJMoa070594

177. Schinke CD, Ashby C, Wang Y, Tytarenko RG, Boyle E, Wardell C, et al. The Mutational Landscape of Primary Plasma Cell Leukemia. Blood (2018) 132:114-4. doi: 10.1182/blood-2018-99-116758

178. Cifola I, Lionetti M, Pinatel E, Todoerti K, Mangano E, Pietrelli A, et al. Whole-exome sequencing of primary plasma cell leukemia discloses heterogeneous mutational patterns. Oncotarget (2015) 6:17543-58. doi: 10.18632 /oncotarget. 4028
Conflict of Interest: The authors declare that the research was conducted in the absence of any commercial or financial relationships that could be construed as a potential conflict of interest.

Copyright (c) 2021 Moser-Katz, Joseph, Dhodapkar, Lee and Boise. This is an openaccess article distributed under the terms of the Creative Commons Attribution License (CC BY). The use, distribution or reproduction in other forums is permitted, provided the original author(s) and the copyright owner(s) are credited and that the original publication in this journal is cited, in accordance with accepted academic practice. No use, distribution or reproduction is permitted which does not comply with these terms. 